Sharif University of Technology
Scientia Iranica
SCIENTIA
I RAN I CA

\title{
A new meta-heuristic algorithm: Vibrating particles system
}

\author{
A. Kaveh ${ }^{a, *}$ and M. Ilchi Ghazaan ${ }^{b}$ \\ a. Centre of Excellence for Fundamental Studies in Structural Engineering, Iran University of Science and Technology, Narmak, \\ Tehran, P.O. Box 16846-13114, Iran. \\ b. School of Civil Engineering, Iran University of Science and Technology, Tehran, P.O. Box 16846-13114, Iran.
}

Received 2 September 2016; accepted 7 September 2016

\section{KEYWORDS}

Vibrating particles system;

Meta-heuristic algorithm;

Global optimization;

Optimal design;

Truss structures;

Frame structures.

\begin{abstract}
In this paper, a new meta-heuristic algorithm based on free vibration of single degree of freedom systems with viscous damping is introduced, and it is called Vibrating Particles System (VPS). The solution candidates are considered as particles that gradually approach their equilibrium positions. Equilibrium positions are achieved from the current population and historically best position in order to have a proper balance between diversification and intensification. To evaluate the performance of the proposed method, it is applied to sizing optimization of four skeletal structures including trusses and frames. Results show that the proposed algorithm is a robust and reliable method.
\end{abstract}

(C) 2017 Sharif University of Technology. All rights reserved.

\section{Introduction}

In recent years, many meta-heuristics with different philosophy and characteristics are introduced and applied to a wide range of fields. The aim of these optimization methods is to efficiently explore the search space in order to find global or near-global solutions. Since they are not problem-specific and do not require the derivatives of the objective function, they have received increasing attention from both academia and industry. Some of the most popular algorithms in this field are: Genetic Algorithms (GA) [1], Particle Swarm Optimization (PSO) [2], Ant Colony Optimization (ACO) [3], Differential Evolution (DE) [4], Harmony Search (HS) [5], Big-Bang BigCrunch (BBBC) [6], Artificial Bee Colony (ABC) [7], Galaxy-based Search Algorithm (GbSA) [8], TeachingLearning-Based Optimization (TLBO) [9], Water Cycle Algorithm (WCA) [10], Colliding Bodies Optimiza-

\footnotetext{
*. Corresponding author. Tel.: +982144202710; Fax: +9821 7ry240398

E-mail address: alikaveh@iust.ac.ir (A. Kaveh)
}

tion (CBO) [11], Grey Wolf Optimizer (GWO) [12], Ant Lion Optimizer (ALO) [13], Tug of War Optimization (TWO) [14], Whale Optimization Algorithm (WOA) [15], and Water Evaporation Optimization (WEO) [16].

A novel population-based meta-heuristic algorithm based on the damped free vibration of single degree of freedom system is introduced in this paper. This algorithm is called a Vibrating Particles System (VPS) algorithm and considers each candidate solution as a particle that approaches its equilibrium position. By utilizing a combination of randomness and exploitation of the obtained results, the quality of the particles improves iteratively as the optimization process proceeds. Here, viability of the proposed method is examined using the optimal design of two truss and two frame structures. The numerical results indicate the efficiency of the proposed algorithm compared to some other methods available in literature. The truss and frame examples are among the most popular class of benchmarks previously studied by researchers [1721].

The remaining sections of this paper are organized 
as follows. The mathematical formulations of the structural optimization are presented in Section 2. The physical background of the VPS algorithm is presented in Section 3, and this new optimization method in detail is introduced in Section 4. The parameter settings are investigated in Section 5. The search behavior of the proposed method and four structural design examples are studied in Section 6. Finally, concluding remarks are provided in Section 7 .

\section{Formulation of the structural optimization problems}

In this study, the objective is to minimize the weight of the structure while satisfying some constraints on stresses and/or buckling and/or deflection and/or natural frequencies. The design variables are cross-sectional areas of structural elements. The mathematical formulation of these problems is expressed as follows:

Find $\quad\{X\}=\left[x_{1}, x_{2}, \ldots, x_{n g}\right]$,

to minimize $\quad W(\{X\})=\sum_{i=1}^{n m} \rho_{i} A_{i} L_{i}$,

Subjected to : $\quad\left\{\begin{array}{l}g_{1}(\{X\}) \leq 0, \quad j=1,2, \ldots, n c \\ x_{i \min } \leq x_{i} \leq x_{i \max }\end{array}\right.$

where $\{X\}$ is a vector containing the design variables; $n g$ is the number of design variable;, $W(\{X\})$ is the weight of the structure; $n m$ is the number of elements of the structure; $\rho_{i}, A_{i}$, and $L_{i}$ denote the material density, cross-sectional area, and the length of the $i$ th member, respectively; $x_{i \min }$ and $x_{i \max }$ are the lower and upper bounds of design variable; $x_{i}$ and respectively; $g_{j}(\{X\})$ denotes design constraints; and $n c$ is the number of constraints.

To handle the constraints, the well-known penalty approach is employed. Thus, the objective function is redefined as follows:

$$
\begin{aligned}
& f(\{X\})=\left(1+\varepsilon_{1} \cdot v\right)^{\varepsilon_{2}} \times W(\{X\}), \\
& v=\sum_{j=1}^{n c} \max \left[0, g_{i}(\{X\})\right],
\end{aligned}
$$

where $v$ denotes the sum of the violations of the design constraints. Constant $\varepsilon_{1}$ is set equal to 1 , while $\varepsilon_{2}$ starts from 1.5 and linearly increases to 3 . Such a scheme penalizes the unfeasible solutions more severely as the optimization process proceeds. As a result, in the early stages, the agents are free to explore the search space, but at the end, they tend to choose solutions with no violation.

\section{The damped free vibration}

A vibration is the oscillating motion of a particle or a body about a position of equilibrium. In general, there are two types of vibrations: (1) free vibration and (2) forced vibration. When the motion is maintained by the restoring forces only, the vibration is said to be a free one, and when a periodic force is applied to the system, the resulting motion is described as a forced vibration. In the study of a vibrating system, the effects of friction can be neglected, resulting in an undamped vibration. However, all vibrations are actually damped to some degree by friction forces. These forces can be caused by dry friction, or Coulomb friction, between rigid bodies by fluid friction when a rigid body moves in a fluid, or by internal friction between the molecules of a seemingly elastic body. In this section, the free vibration of single degree of freedom systems with viscous damping is studied. The viscous damping is caused by fluid friction at low and moderate speeds. Viscous damping is characterized by the fact that the friction force is directly proportional and opposite to the velocity of the moving body [22].

The vibrating motion of a body or system of mass, $m$, having viscous damping can be characterized by a block and spring of constant, $k$, as shown in Figure 1. The effect of damping is provided by the dashpot connected to the block, and the magnitude of the friction force exerted on the plunger by the surrounding fluid is equal to $c \dot{x}$ ( $c$ is the coefficient of viscous damping, and its value depends on the physical properties of the fluid and the construction of the dashpot). If the block is displaced at distance $x$ from its equilibrium position, the equation of motion can be expressed as:

$$
m \ddot{x}+c \dot{x}+k x=0
$$

Before presenting the solutions to this differential

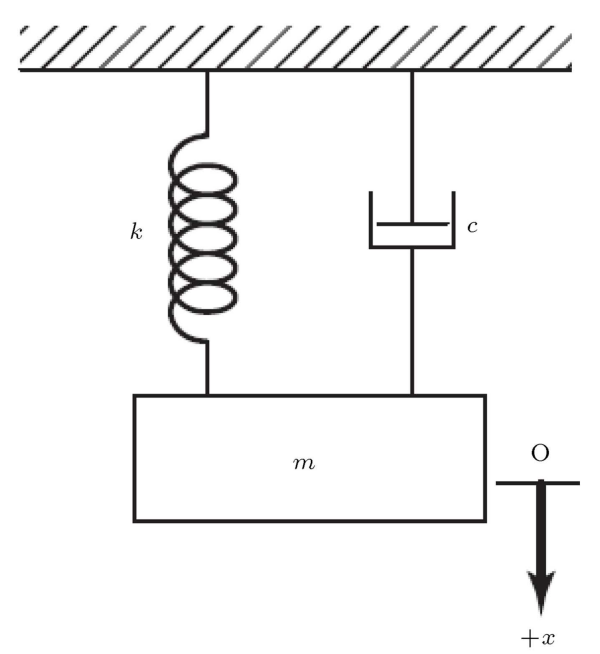

Figure 1. Free vibration of a system with damping. 
equation, we define critical damping coefficient, $c_{c}$, as:

$$
\begin{aligned}
c_{c} & =2 m \omega_{n}, \\
\omega_{n} & =\sqrt{\frac{k}{m}},
\end{aligned}
$$

where $\omega_{n}$ is the natural circular frequency of the vibration.

Depending on the value of the coefficient of viscous damping, three different cases of damping can be distinguished: (1) over-damped system $\left(c>c_{c}\right) ;(2)$ critically damped system $\left(c=c_{c}\right) ;(3)$ under-damped system $\left(c<c_{c}\right)$. The solutions to over-damped and critically damped system correspond to a non-vibratory motion. Therefore, the system only oscillates and returns to its equilibrium position when $c<c_{c}$.

The solution of Eq. (3) for under-damped system is as follows:

$$
\begin{aligned}
& x(t)=\rho e^{-\xi \omega_{n} t} \sin \left(\omega_{D} t+\phi\right), \\
& \omega_{D}=\omega_{n} \sqrt{1-\xi^{2}}, \\
& \xi=\frac{c}{2 m \omega_{n}},
\end{aligned}
$$

where $\rho$ and $\phi$ are constants generally determined from the initial conditions of the problem. $\omega_{D}$ and $\xi$ are damped natural frequency and damping ratio, respectively. Eq. (6) is shown in Figure 2, and the effect of damping ratio on vibratory motion is illustrated in Figure 3.

\section{A new meta-heuristic algorithm based on the vibrating particles system}

The vibrating particles system is a meta-heuristic method inspired by the free vibration of single degree of freedom systems with viscous damping. The VPS involves a number of candidate solutions representing the particles system. The particles are initialized randomly in an $n$-dimensional search space and gradually approach their equilibrium positions. The pseudo-code of VPS is provided in Figure 4, and the steps involved are given as follows:

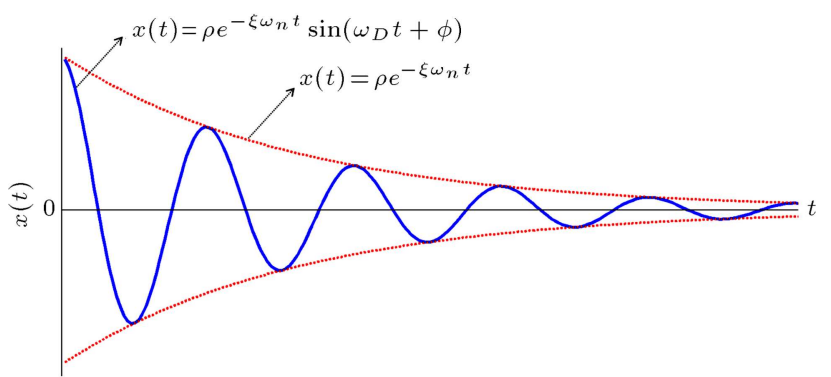

Figure 2. Vibrating motion of under-damped system.

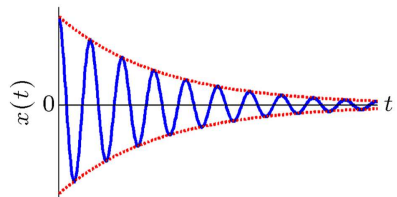

(a)

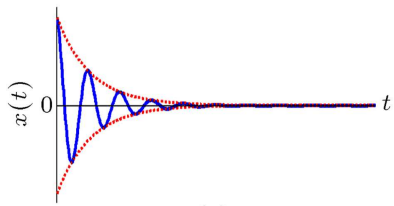

(c)

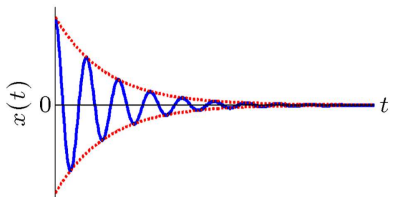

(b)

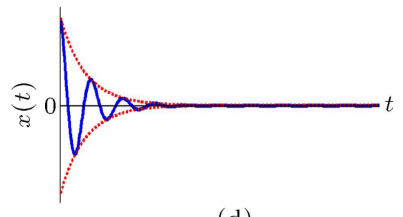

(d)
Figure 3. Free vibration of systems with four levels of damping: (a) $\xi=5 \%$, (b) $\xi=10 \%$, (c) $\xi=15 \%$, and (d) $\xi=20 \%$.

- Step 1: Initialization: The VPS parameters are set, and the initial positions of all particles are determined randomly in an $n$-dimensional search space.

- Step 2: Evaluation of candidate solutions: The objective function value is calculated for each particle.

- Step 3: Updating the particle positions: For each particle, three equilibrium positions with different weights are defined that the particle tends to approach: (1) the best position achieved so far across the entire population $(H B)$; (2) a Good Particle $(G P)$; and $(3)$ a Bad Particle $(B P)$. In order to select $G P$ and $B P$ for each candidate solution, the current population is sorted according to their objective function values in an increasing order, and then $G P$ and $B P$ are chosen randomly from the first and second halves, respectively.

Figure 3 shows the important effect of damping level on the vibration. In order to model this phenomenon in the optimization algorithm, a descending function that is proportional to the number of iterations is proposed as follows:

$$
D=\left(\frac{i t e r}{i t e r_{\max }}\right)^{-\alpha},
$$

where iter is the current iteration number, and iter $_{\max }$ is the total number of iteration for optimization process. $\alpha$ is a constant, and Figure 5 shows the effect of this parameter on $D$.

According to the mentioned concepts, the positions are updated by:

$$
\begin{aligned}
x_{i}^{j}= & w_{1} \cdot\left[\text { D.A.rand } 1+H B^{j}\right] \\
& +w_{2} \cdot\left[\text { D.A.rand } 2+G P^{j}\right] \\
& +w_{3} \cdot\left[\text { D.A.rand } 3+B P^{j}\right],
\end{aligned}
$$




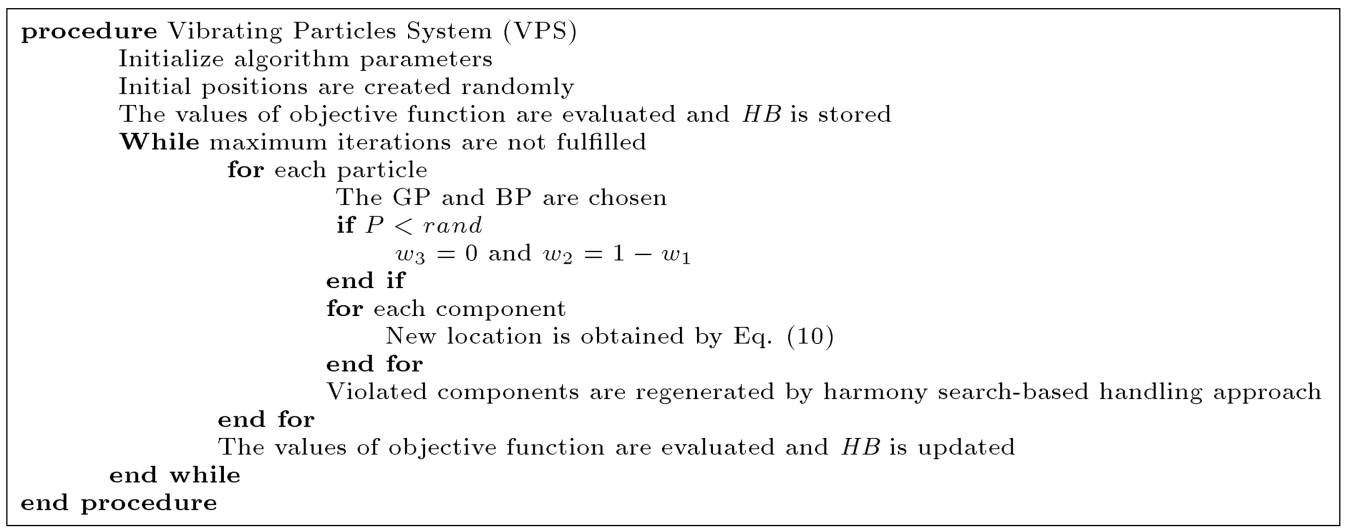

Figure 4. Pseudo code of the vibrating particles system algorithm.

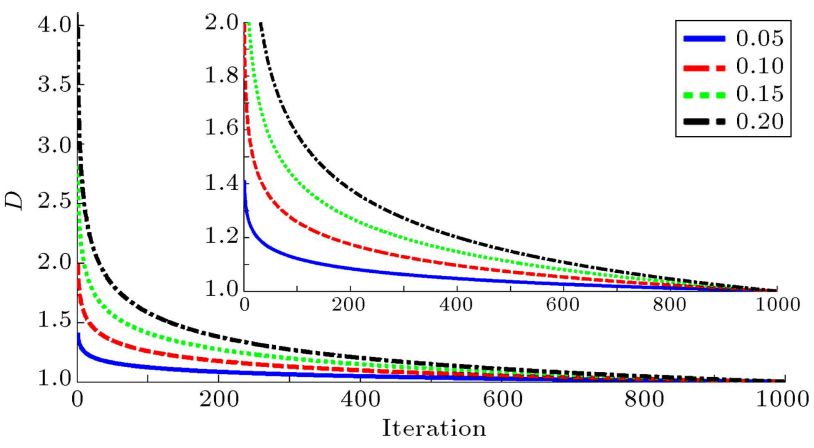

Figure 5. The influence of $\alpha$ on $D$ function.

$$
\begin{aligned}
A & =\left[w_{1} \cdot\left(H B^{j}-x_{i}^{j}\right)\right]+\left[w_{2} \cdot\left(G P^{j}-x_{i}^{j}\right)\right] \\
& +\left[w_{3} \cdot\left(B P^{j}-x_{i}^{j}\right)\right] \\
w_{1} & +w_{2}+w_{3}=1
\end{aligned}
$$

where $x_{i}^{j}$ is the $j$ th variable of particle $i ; w_{1}, w_{2}$, and $w_{3}$ are three parameters to measure the relative importance of $H B, G P$, and $B P$, respectively. rand1, rand 2 , and rand 3 are random numbers uniformly distributed in the range of $[0,1]$. The effects of $A$ and $D$ parameters in Eq. (10) are similar to those of $\rho$ and $e^{-\xi \omega_{n} t}$ in Eq. (6), respectively. Also, the value of $\sin \left(\omega_{D} t+\phi\right)$ is considered unity in Eq. (10) $\left(x(t)=\rho e^{-\xi \omega_{n} t}\right.$ is shown in Figure 2 by red lines).

A parameter like $p$ within $(0,1)$ is defined, and it is specified whether the effect of $B P$ must be considered in updating position or not. For each particle, $p$ is compared with rand (a random number uniformly distributed in the range of $[0,1])$; if $p<$ rand, then $w_{3}=0$ and $w_{2}=1-w_{1}$.

Three essential concepts, consisting of selfadaptation, cooperation, and competition, are considered in this algorithm. Particle moves towards $H B$, so the self-adaptation is provided. Any particle has the chance to have influence on the new position of the other one, so the cooperation between the par- ticles is supplied. Due to $p$ parameter, the influence of GP (Good Particle) is more than that of BP (Bad Particle); therefore, the competition is provided.

- Step 4: Handling the side constraints: The particle moves in the search space to find a better result, and it may violate the side constraints. If any component of the system violates a boundary, it must be regenerated by harmony search-based side constraint-handling approach [23]. In this technique, there is a possibility like HMCR (Harmony Memory Considering Rate) that specifies whether the violating component must be changed with the corresponding component of the historically best position of a random particle, or it should be determined randomly in the search space. Moreover, if the component of a historically best position is selected, there is a possibility like PAR (Pitch Adjusting Rate) that specifies whether this value should be changed with the neighboring value or not.

- Step 5: Terminating criterion controlling: Steps 2 to 4 are repeated until a termination criterion is fulfilled. Any terminating condition can be considered, and in this study, the optimization process is terminated after a fixed number of iterations.

\section{Search behavior of the vibrating particles system algorithm}

In order to evaluate the effect of the algorithm parameters on the optimization results, a spatial 120bar dome shaped truss (Section 6.1) is considered as a benchmark. The effect of the population size, the maximum number of structural analyses (population size $\times$ total number of iterations), $\alpha, p, w_{1}$, and $w_{2}$ are investigated in this section. In the first step, these parameters are set to $20,20000,0.15,70 \%, 0.3$, and 0.3 , respectively, and then their proper values are obtained one after another.

Tables 1 and 2 summarize the statistical results achieved for different values of population size $(10$, 
Table 1. Sensitivity analysis on population size.

\begin{tabular}{lcccc}
\hline & $\mathbf{1 0}$ & $\mathbf{2 0}$ & $\mathbf{3 0}$ & $\mathbf{4 0}$ \\
\hline Best optimized weight (lb) & $33,262.75$ & $33,250.27$ & $33,255.65$ & $33,471.79$ \\
Worst optimized weight (lb) & $33,413.99$ & $33,282.16$ & $33,432.60$ & $33,903.75$ \\
Average optimized weight (lb) & $33,322.28$ & $33,258.58$ & $33,315.24$ & $33,668.73$ \\
Standard deviation on average weight (lb) & 51.49 & 10.31 & 62.77 & 130.71 \\
Number of structural analyses for the best design & 8,920 & 19,780 & 13,060 & 9,780 \\
Average number of structural analysis & 10,106 & 16,930 & 12,746 & 7,958 \\
\hline
\end{tabular}

Table 2. Sensitivity analysis on maximum number of iterations.

\begin{tabular}{lcccc}
\hline & $\mathbf{7 5 0}$ & $\mathbf{1 0 0 0}$ & $\mathbf{1 2 5 0}$ & $\mathbf{1 5 0 0}$ \\
\hline Best optimized weight (lb) & $33,251.34$ & $33,250.27$ & $33,250.83$ & $33,250.24$ \\
Worst optimized weight (lb) & $33,283.49$ & $33,282.16$ & $33,275.18$ & $33,265.92$ \\
Average optimized weight (lb) & $33,263.52$ & $33,258.59$ & $33,255.03$ & $33,257.01$ \\
Standard deviation on average weight (lb) & 12.75 & 10.31 & 7.71 & 5.97 \\
Number of structural analyses for the best design & 12,620 & 19,780 & 20,800 & 22,320 \\
Average number of structural analysis & 13,094 & 16,930 & 18,646 & 20,802 \\
\hline
\end{tabular}

20,30 , and 40) and total number of iterations (750, 1000, 1250, and 1500), respectively. As it can be seen from Table 1, when population size is 20, the VPS has a better performance in terms of the best weight, worst weight, average optimized weight, and standard deviation on average weight. Table 2 demonstrates that considering 1500 iterations can surely be the most efficient value for the total number of iterations. The corresponding average convergence curves are shown in Figure 6. Since the maximum number of structural analyses is set to 20000 in Figure 6(a), the total number of iterations for $10,20,30$, and 40 particles is 2000 , 1000,667 , and 500, respectively, considered as the termination criterion.

Performance of the VPS with different values of $\alpha(0.05,0.1,0.15$, and 0.2$)$ and $p(60 \%, 70 \%, 80 \%$, and $90 \%$ ) is compared in Tables 3 and 4, respectively. When $\alpha$ is considered as 0.1 , the best weight is achieved; however, comparison of the other variables shows that 0.05 is generally the most suitable value for $\alpha$. It can be concluded from Table 4 that $70 \%$ is the most efficient value for $p$. Average convergence histories are depicted in Figure 7. As mentioned before, the influence of damping level on vibration is similar to the effect of $\alpha$ on particles convergence as can be seen in Figure $7(\mathrm{a})$. To make the curves of Figure $7(\mathrm{~b})$ clearer, the magnified version of lower part is also shown.

Results of sensitivity analysis on $w_{1}$ and $w_{2}$ are shown in Tables 5 and 6 . According to the statistical results reported in these tables, the most suitable performance of the VPS is obtained when the value of 0.3 is considered for $w_{1}$ and $w_{2}$. Figure 8 compares the average convergence curves. It can be seen from Figure $8(\mathrm{a})$ that by decreasing the value of $w_{1}$ (decreasing

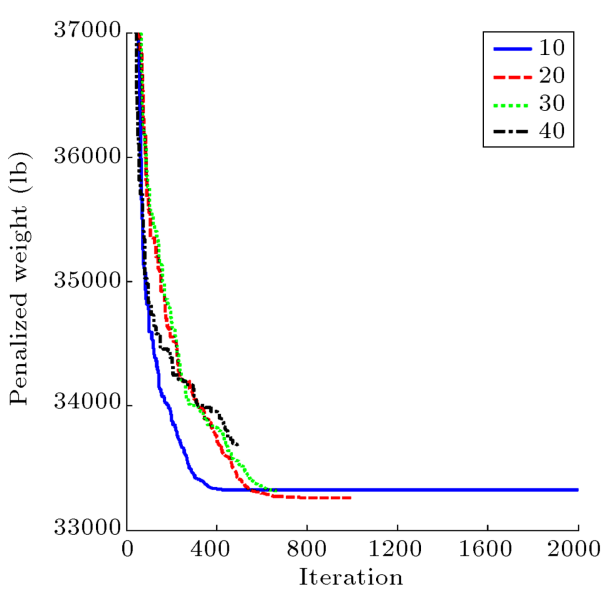

(a)

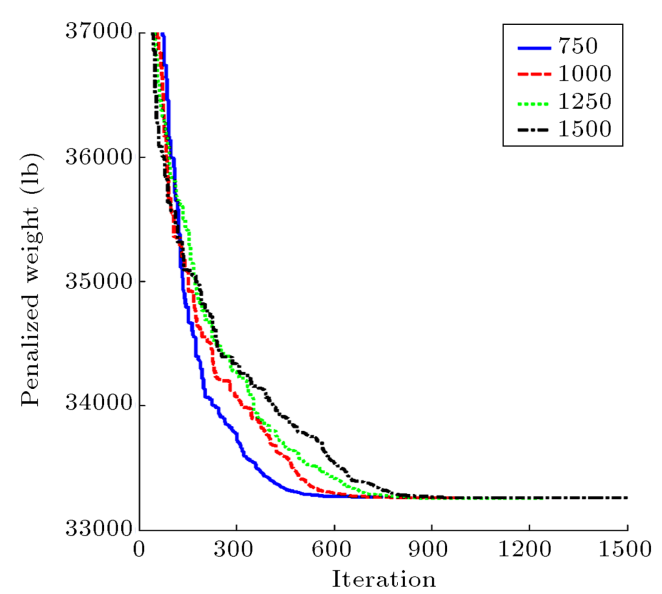

(b)

Figure 6. Sensitivity analysis on (a) population size and (b) maximum number of iterations. 
Table 3. Sensitivity analysis on $\alpha$.

\begin{tabular}{lcccc}
\hline & $\mathbf{0 . 0 5}$ & $\mathbf{0 . 1}$ & $\mathbf{0 . 1 5}$ & $\mathbf{0 . 2}$ \\
\hline Best optimized weight (lb) & $33,249.98$ & $33,249.76$ & $33,250.24$ & $33,249.98$ \\
Worst optimized weight (lb) & $33,262.74$ & $33,283.46$ & $33,265.92$ & $33,261.82$ \\
Average optimized weight (lb) & $33,253.56$ & $33,254.91$ & $33,257.01$ & $33,254.02$ \\
Standard deviation on average weight (lb) & 4.36 & 10.31 & 5.97 & 3.89 \\
Number of structural analyses for the best design & 8,280 & 17,500 & 22,320 & 24,180 \\
Average number of structural analysis & 9,846 & 17,794 & 20,802 & 24,834 \\
\hline
\end{tabular}

Table 4. Sensitivity analysis on $p$.

\begin{tabular}{lcccc}
\hline & $\mathbf{6 0 \%}$ & $\mathbf{7 0 \%}$ & $\mathbf{8 0 \%}$ & $\mathbf{9 0 \%}$ \\
\hline Best optimized weight (lb) & $33,250.06$ & $33,249.98$ & $33,250.89$ & $33,250.08$ \\
Worst optimized weight (lb) & $33,260.61$ & $33,262.74$ & $33,257.86$ & $33,281.97$ \\
Average optimized weight (lb) & $33,254.03$ & $33,253.56$ & $33,253.23$ & $33,256.93$ \\
Standard deviation on average weight (lb) & 4.27 & 4.36 & 2.54 & 9.75 \\
Number of structural analyses for the best design & 12,900 & 8,280 & 10,580 & 10,740 \\
Average number of structural analysis & 11,114 & 9,846 & 11,910 & 10,104 \\
\hline
\end{tabular}

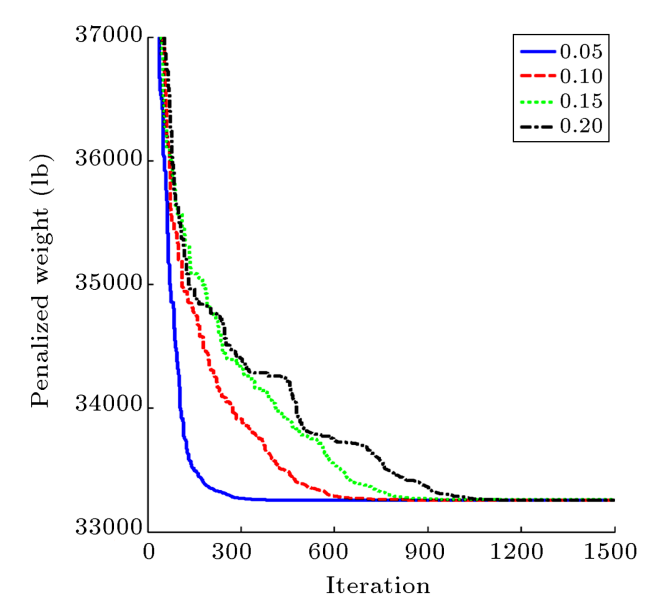

(a)

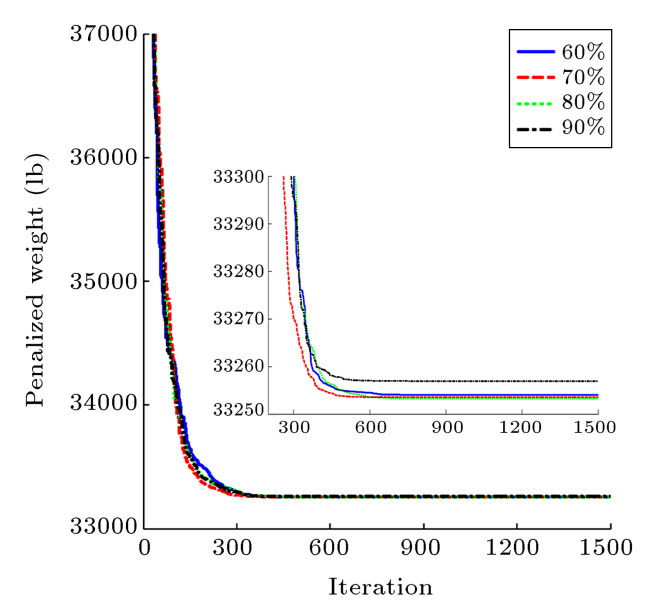

(b)

Figure 7. Sensitivity analysis on (a) $\alpha$ and (b) $p$.

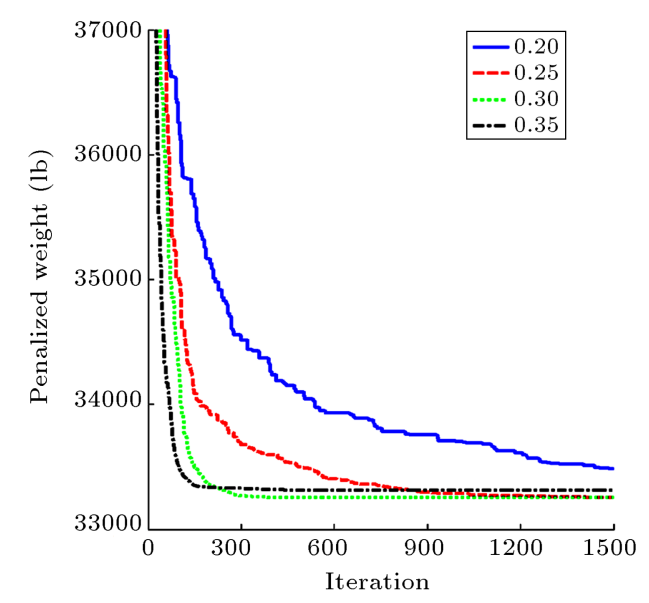

(a)

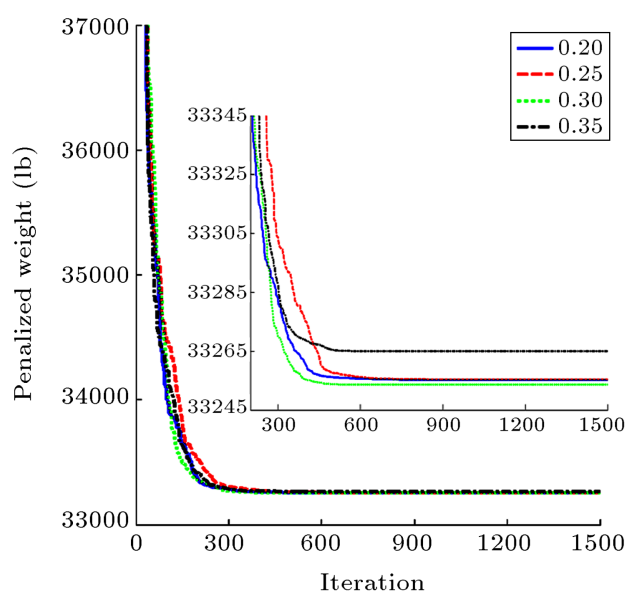

(b)

Figure 8. Sensitivity analysis on (a) $w_{1}$ and (b) $w_{2}$. 
Table 5. Sensitivity analysis on $w_{1}$.

\begin{tabular}{lcccc}
\hline & $\mathbf{0 . 2}$ & $\mathbf{0 . 2 5}$ & $\mathbf{0 . 3}$ & $\mathbf{0 . 3 5}$ \\
\hline Best optimized weight (lb) & $33,386.52$ & $33,250.16$ & $33,249.98$ & $33,252.79$ \\
Worst optimized weight (lb) & $33,655.38$ & $33,268.67$ & $33,262.74$ & $33,676.11$ \\
Average optimized weight (lb) & $33,484.02$ & $33,254.51$ & $33,253.56$ & $33,314.71$ \\
Standard deviation on average weight (lb) & 83.68 & 5.38 & 4.36 & 130.57 \\
Number of structural analyses for the best design & 28,820 & 28,540 & 8,280 & 5,160 \\
Average number of structural analysis & 26,456 & 28,342 & 9,846 & 6,520 \\
\hline
\end{tabular}

Table 6. Sensitivity analysis on $w_{2}$.

\begin{tabular}{lcccc}
\hline & $\mathbf{0 . 2}$ & $\mathbf{0 . 2 5}$ & $\mathbf{0 . 3}$ & $\mathbf{0 . 3 5}$ \\
\hline Best optimized weight (lb) & $33,250.63$ & $33,249.67$ & $33,249.98$ & $33,250.62$ \\
Worst optimized weight (lb) & $33,268.43$ & $33,271.20$ & $33,262.74$ & $33,321.25$ \\
Average optimized weight (lb) & $33,255.19$ & $33,255.38$ & $33,253.56$ & $33,264.93$ \\
Standard deviation on average weight (lb) & 5.06 & 6.49 & 4.36 & 22.84 \\
Number of structural analyses for the best design & 12,940 & 12,180 & 8,280 & 12,880 \\
Average number of structural analysis & 11,982 & 12,196 & 9,846 & 9,954 \\
\hline
\end{tabular}

the effect of $H B$ position in updating formula), the explorations are increased, and vice versa. To make the curves of Figure 8(b) clearer, the magnified version of lower part is also added.

In summary, the values of population size, the total number of iteration, $\alpha, p, w_{1}$, and $w_{2}$ are set to $20,1500,0.05,70 \%, 0.3$, and 0.3 for all examples, respectively.

\section{Test problems and optimization results}

Four skeletal structures are optimized for minimum weight with the cross-sectional areas of the members being the design variables to evaluate the performance of the proposed method. The examples are classified into 2 groups: The first group consists of two truss structures with the number of truss bars of 120 and 200 , respectively; the second group includes two steel frames having 105 and 168 members, respectively. For all the considered examples, 20 independent optimization runs are carried out as meta-heuristic algorithms have stochastic nature and their performance may be sensitive to initial population. The algorithm is coded in MATLAB, and the structures are analyzed using the direct stiffness method by our own codes.

\subsection{A spatial 120-bar dome shaped truss}

The schematic and element grouping of the spatial 120bar dome truss are shown in Figure 9. The structure is divided into 7 groups of elements due to symmetry (for the sake of clarity, not all the element groups are numbered in Figure 9). The modulus of elasticity is $30,450 \mathrm{ksi}(210 \mathrm{GPa})$, and the material density is 0.288 $\mathrm{lb} / \mathrm{in}^{3}\left(7971.810 \mathrm{~kg} / \mathrm{m}^{3}\right)$. The yield stress of steel is

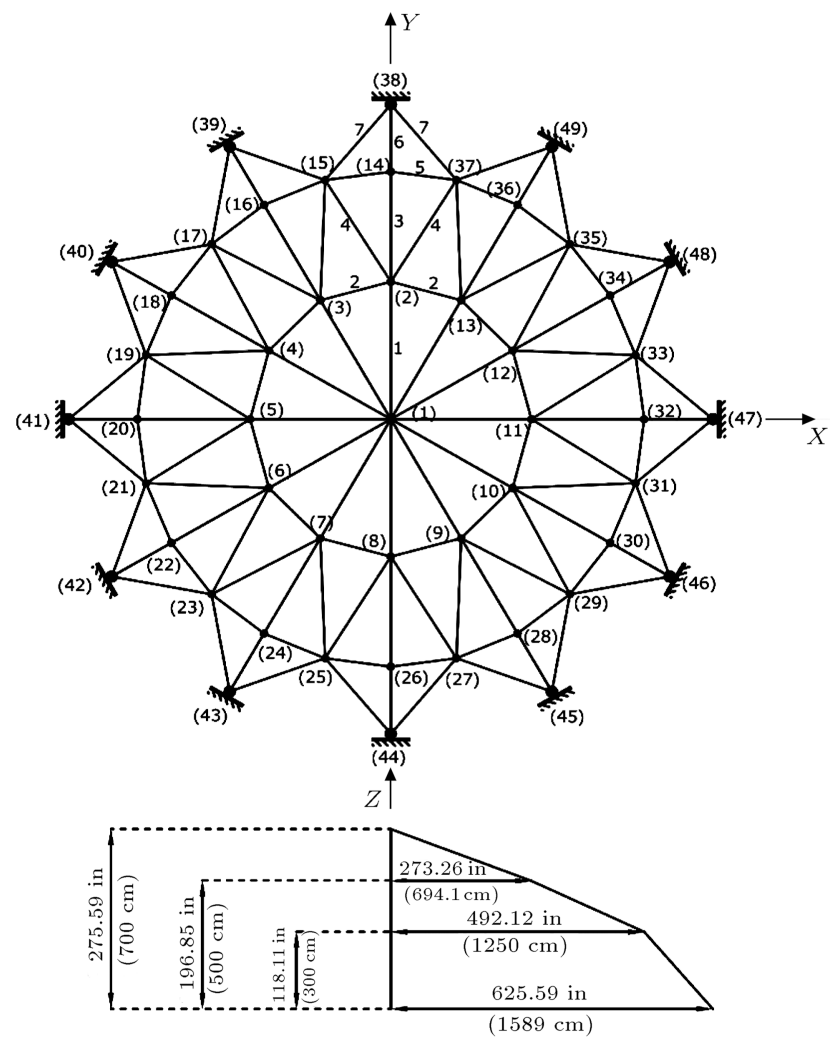

Figure 9. Schematic of the spatial 120-bar dome shaped truss.

taken as $58.0 \mathrm{ksi}$ (400 MPa). The dome is considered to be subjected to vertical loading at all the unsupported joints. These loads are taken as -13.49 kips $(-60 \mathrm{kN})$ at node $1,-6.744$ kips $(-30 \mathrm{kN})$ at nodes 2 through 14 , and -2.248 kips $(-10 \mathrm{kN})$ in the rest of the nodes. Element cross-sectional areas can vary between $0.775 \mathrm{in}^{2}\left(5 \mathrm{~cm}^{2}\right)$ 
Table 7. Performance comparison for the spatial 120-bar dome shaped truss structure.

\begin{tabular}{|c|c|c|c|c|c|c|c|}
\hline \multirow[b]{2}{*}{$\begin{array}{l}\text { Element } \\
\text { group }\end{array}$} & \multicolumn{7}{|c|}{ Optimal cross-sectional areas $\left(\mathrm{in}^{2}\right)$} \\
\hline & $\begin{array}{l}\text { CSS } \\
{[25]}\end{array}$ & $\begin{array}{c}\text { IRO } \\
{[26]} \\
\end{array}$ & $\begin{array}{c}\text { MSPSO } \\
{[27]} \\
\end{array}$ & $\begin{array}{c}\text { CBO } \\
{[11]} \\
\end{array}$ & $\begin{array}{c}\text { TWO } \\
{[14]} \\
\end{array}$ & $\begin{array}{c}\text { WEO } \\
{[16]}\end{array}$ & $\begin{array}{c}\text { Present } \\
\text { work }\end{array}$ \\
\hline 1 & 3.027 & 3.0252 & 3.0244 & 3.0273 & 3.0247 & 3.0243 & 3.0244 \\
\hline 2 & 14.606 & 14.8354 & 14.7804 & 15.1724 & 14.7261 & 14.7943 & 14.7536 \\
\hline 3 & 5.044 & 5.1139 & 5.0567 & 5.2342 & 5.1338 & 5.0618 & 5.0789 \\
\hline 4 & 3.139 & 3.1305 & 3.1359 & 3.119 & 3.1369 & 3.1358 & 3.1371 \\
\hline 5 & 8.543 & 8.4037 & 8.4830 & 8.1038 & 8.4545 & 8.4870 & 8.4829 \\
\hline 6 & 3.367 & 3.3315 & 3.3104 & 3.4166 & 3.2946 & 3.2886 & 3.3012 \\
\hline 7 & 2.497 & 2.4968 & 2.4977 & 2.4918 & 2.4956 & 2.4967 & 2.4963 \\
\hline Weight (lb) & $33,251.9$ & $33,256.48$ & $33,251.22$ & $33,286.3$ & $33,250.31$ & $33,250.24$ & $33,249.98$ \\
\hline $\begin{array}{l}\text { Average optimized } \\
\text { weight }(\mathrm{lb})\end{array}$ & $\mathrm{N} / \mathrm{A}$ & $33,280.85$ & $33,257.29$ & $33,398.5$ & $33,282.64$ & $33,255.55$ & $33,253.56$ \\
\hline $\begin{array}{l}\text { Standard deviation } \\
\text { on average weight (lb) }\end{array}$ & $\mathrm{N} / \mathrm{A}$ & $\mathrm{N} / \mathrm{A}$ & 4.29 & 67.09 & 25.38 & $\mathrm{~N} / \mathrm{A}$ & 4.36 \\
\hline $\begin{array}{c}\text { Number of } \\
\text { structural analyses }\end{array}$ & 7,000 & 18,300 & 15,000 & 14,960 & 16,000 & 19,510 & 8,280 \\
\hline
\end{tabular}

and $20.0 \mathrm{in}^{2}\left(129.032 \mathrm{~cm}^{2}\right)$. Displacement limitations of \pm 0.1969 in $( \pm 5 \mathrm{~mm})$ are imposed on all nodes in $x$ $y$, and $z$ coordinate directions. Constraints on member stresses are imposed according to the provisions of the AISC [24] as follows.

The allowable tensile stresses for tension members are calculated as:

$$
\sigma_{i}^{+}=0.6 F_{y}
$$

where $F_{y}$ is the yield strength.

The allowable stress limits for compression members are calculated depending on two possible failure modes of the members, known as elastic and inelastic buckling. Therefore:

$$
\sigma_{i}^{-}=\left\{\begin{array}{cl}
{\left[\left(1-\frac{\lambda_{i}^{2}}{2 C_{c}^{2}}\right) F_{y}\right]} & \\
/\left[\frac{5}{3}+\frac{3 \lambda_{i}}{8 C_{c}}-\frac{\lambda_{i}^{3}}{8 C_{c}^{3}}\right] & \text { for } \lambda_{i}<C_{c} \\
\frac{12 \pi^{2} E}{23 \lambda_{i}^{2}} & \text { for } \lambda_{i} \geq C_{c}
\end{array}\right.
$$

where $E$ is the modulus of elasticity, $\lambda_{i}$ is the slenderness ratio $\left(\lambda_{i}=k l_{i} / r_{i}\right), C_{c}$ denotes the slenderness ratio dividing the elastic and inelastic buckling regions $C_{c}=\sqrt{2 \pi^{2} E / F_{y}}, k$ is the effective length factor ( $k$ is set equal to 1 for all truss members), $L_{i}$ is the member length, and $r_{i}$ is the minimum radius of gyration.

This truss was previously optimized by CSS (Charged System Search algorithm) [25], IRO (Improved Ray Optimization) [26], MSPSO (Multi-Stage Particle Swarm Optimization) [27], CBO (Colliding Bodies Optimization) [11], TWO (Tug of War Optimization) [14], and WEO (Water Evaporation Optimization) [16].

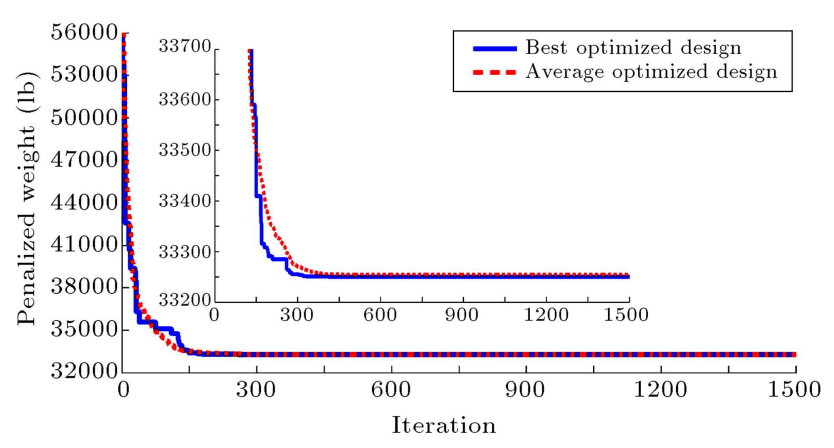

Figure 10. Convergence curves obtained for the 120-bar dome shaped truss problem.

Comparison of the optimal designs obtained by this work with those of the other studies is given in Table 7 . It can be seen that the lightest design (i.e., $33,249.98 \mathrm{lb}$ ) and the best average optimized weight (i.e., 33,253.56 lb) are found by the proposed method. The VPS converges with the optimum solution after 8,280 analyses. The CSS gives the best result as $33,251,9 \mathrm{lb}$ in 7,000 analyses. However, the VPS achieves this result after 6,400 analyses. Figure 10 compares the convergence curves of the best and the average results obtained by the proposed method.

\subsection{A 200-bar planar truss}

The second structural optimization problem solved in this research is the optimal design of the 200-bar planar truss schematized in Figure 11. Due to the symmetry, the elements are divided into 29 groups. The modulus of elasticity and the material density of members are $210 \mathrm{GPa}$ and $7,860 \mathrm{~kg} / \mathrm{m}^{3}$, respectively. Non-structural masses of $100 \mathrm{~kg}$ are attached to the upper nodes. 


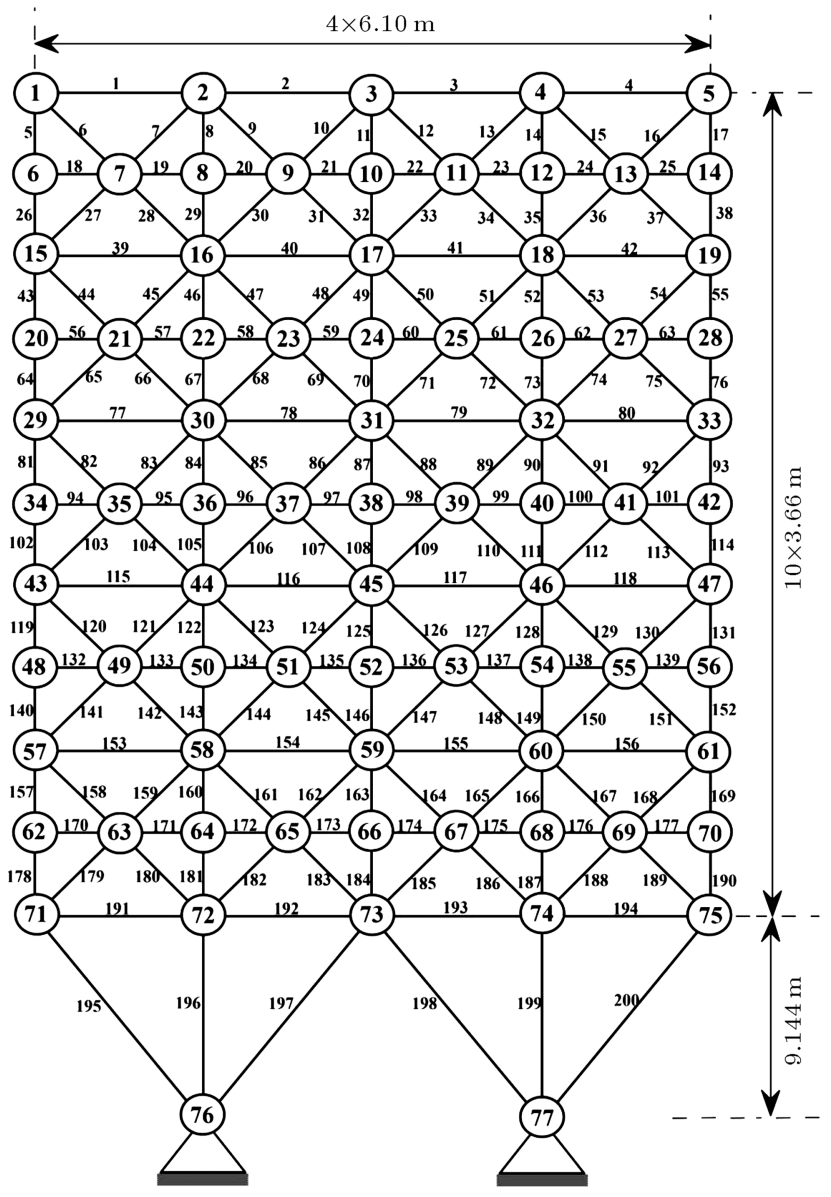

Figure 11. Schematic of the 200-bar planar truss.

A lower bound of $0.1 \mathrm{~cm}^{2}$ is assumed for the crosssectional areas. The first three natural frequencies of the structure must satisfy the following limitations: $\left(f_{1} \geq 5 \mathrm{~Hz}, f_{2} \geq 10 \mathrm{~Hz}, f_{3} \geq 15 \mathrm{~Hz}\right)$.

Table 8 presents the results of the optimal designs utilizing CSS-BBBC (a hybridization of the charged system search and the big bang-big crunch algorithms with trap recognition capability) [28], CBO (Colliding Bodies Optimization) [29], ECBO (Enhanced Colliding Bodies Optimization) [29], CBO-PSO (a hybrid of CBO and PSO algorithms) [30], and the proposed method. The weight of the best result obtained by VPS is $2,156.62 \mathrm{~kg}$ that is the best among the compared methods. Moreover, the average optimized weight for 20 independent optimization runs of the VPS is $2,159.46 \mathrm{~kg}$ which is less than those of all other methods. The first three natural frequencies of the structure for the best design are $5.0000 \mathrm{~Hz}$, $12.2086 \mathrm{~Hz}$, and $15.0153 \mathrm{~Hz}$. The proposed method requires 16,420 structural analyses to find the optimum solution, while CBO, ECBO, and CBO-PSO require $10,500,14,700$, and 9,000 structural analyses, respectively. It should be noted that the designs found by VPS at 9,000th, 10,500th, and 14,700th analyses are $2,158.35 \mathrm{~kg}, 2,158.06 \mathrm{~kg}$, and $2,157.72 \mathrm{~kg}$,

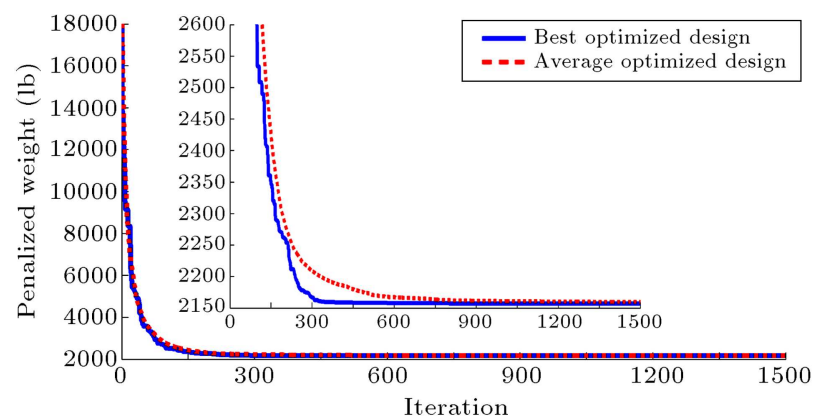

Figure 12. Convergence curves obtained for the 200-bar planar truss problem.

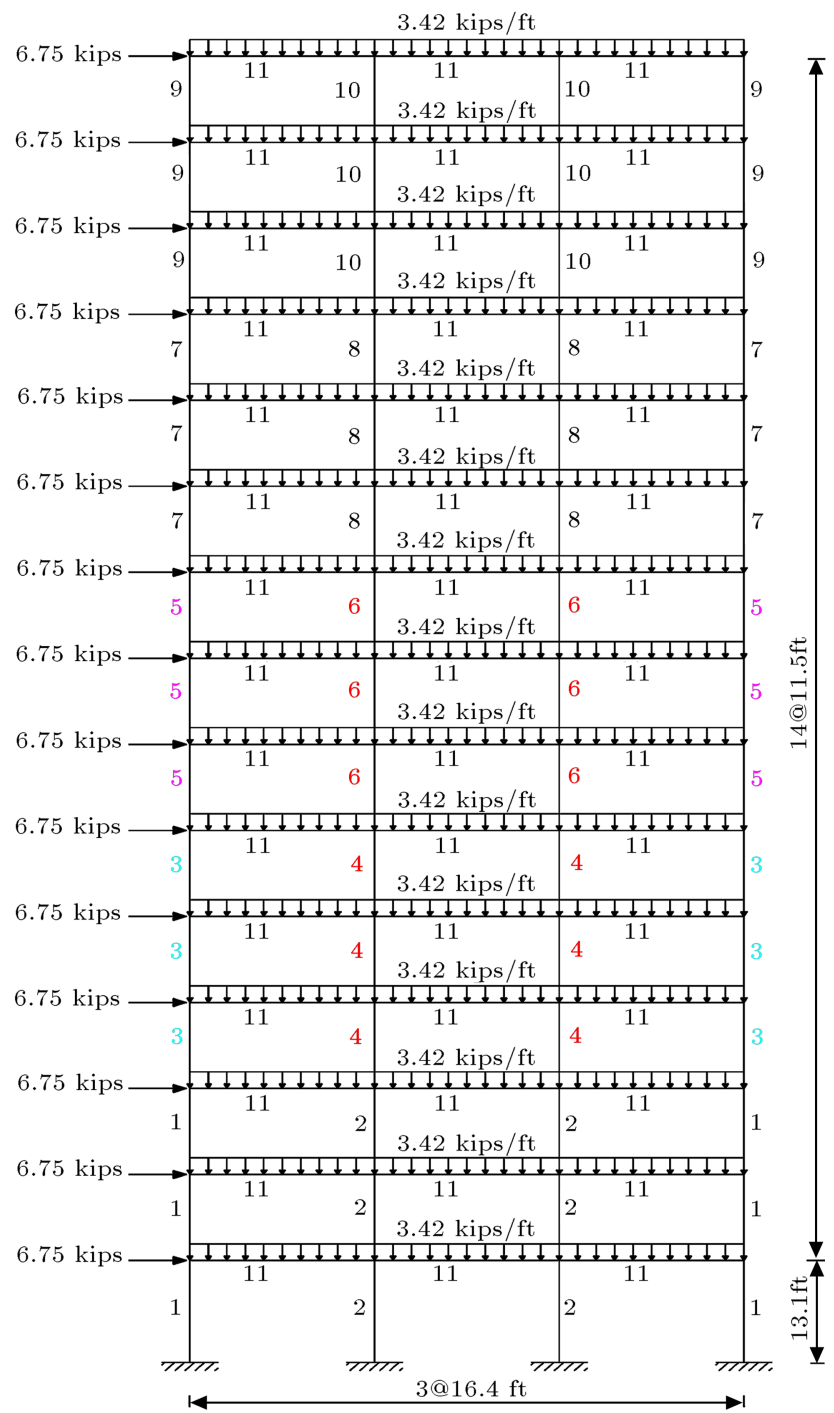

Figure 13. Schematic of the 3-bay 15-story frame.

respectively. Comparison of the convergence rates between the best and the average curves of VPS is illustrated in Figure 12.

\subsection{A 3-bay 15-story frame problem}

Figure 13 represents the schematic of the 3-bay 15story frame. The applied loads and the numbering 
Table 8. Performance comparison for the 200-bar planar truss structure.

\begin{tabular}{|c|c|c|c|c|c|c|}
\hline \multirow{2}{*}{$\begin{array}{l}\text { Element } \\
\text { group }\end{array}$} & \multirow{2}{*}{$\begin{array}{l}\text { Members in } \\
\text { the group }\end{array}$} & \multicolumn{5}{|c|}{ Areas $\left(\mathrm{cm}^{2}\right)$} \\
\hline & & $\begin{array}{c}\text { CSS-BBBC } \\
{[28]} \\
\end{array}$ & $\begin{array}{c}\text { CBO } \\
{[29]} \\
\end{array}$ & $\begin{array}{c}\text { ECBO } \\
{[29]}\end{array}$ & $\begin{array}{c}\text { CBO-PSO } \\
{[30]} \\
\end{array}$ & $\begin{array}{c}\text { Present } \\
\text { work }\end{array}$ \\
\hline 1 & $1,2,3,4$ & 0.2934 & 0.3059 & 0.2993 & 0.2797 & 0.3031 \\
\hline 2 & $5,8,11,14,17$ & 0.5561 & 0.4476 & 0.4497 & 0.6968 & 0.4496 \\
\hline 3 & $19,20,21,22,23,24$ & 0.2952 & 0.1000 & 0.1000 & 0.1000 & 0.1002 \\
\hline 4 & $18,25,56,63,94,101,132,139,170,177$ & 0.1970 & 0.1001 & 0.1000 & 0.1000 & 0.1000 \\
\hline 5 & $26,29,32,35,38$ & 0.8340 & 0.4944 & 0.5137 & 0.5796 & 0.5086 \\
\hline 6 & $\begin{array}{c}6,7,9,10,12,13,15,16,27,28 \\
30,31,33,34,36,37\end{array}$ & 0.6455 & 0.8369 & 0.7914 & 0.8213 & 0.8204 \\
\hline 7 & $39,40,41,42$ & 0.1770 & 0.1001 & 0.1013 & 0.1279 & 0.1000 \\
\hline 8 & $43,46,49,52,55$ & 1.4796 & 1.5514 & 1.4129 & 1.0152 & 1.4210 \\
\hline 9 & $57,58,59,60,61,62$ & 0.4497 & 0.1000 & 0.1019 & 0.1000 & 0.1002 \\
\hline 10 & $64,67,70,73,76$ & 1.4556 & 1.5286 & 1.6460 & 1.5647 & 1.5900 \\
\hline 11 & $\begin{array}{l}44,45,47,48,50,51,53,54 \\
65,66,68,69,71,72,74,75\end{array}$ & 1.2238 & 1.1547 & 1.1532 & 1.6465 & 1.1530 \\
\hline 12 & $77,78,79,80$ & 0.2739 & 0.1000 & 0.1000 & 0.2296 & 0.1277 \\
\hline 13 & $81,84,87,90,93$ & 1.9174 & 2.9980 & 3.1850 & 2.9007 & 2.9160 \\
\hline 14 & $95,96,97,98,99,100$ & 0.1170 & 0.1017 & 0.1034 & 0.1000 & 0.1009 \\
\hline 15 & $102,105,108,111,114$ & 3.5535 & 3.2475 & 3.3126 & 3.0133 & 3.2826 \\
\hline 16 & $\begin{array}{c}82,83,85,86,88,89,91,92,103, \\
104,106,107,109,110,112,113\end{array}$ & 1.3360 & 1.5213 & 1.5920 & 1.6142 & 1.5856 \\
\hline 17 & $115,116,117,118$ & 0.6289 & 0.3996 & 0.2238 & 0.2755 & 0.2794 \\
\hline 18 & $119,122,125,128,131$ & 4.8335 & 4.7557 & 5.1227 & 5.0951 & 5.0680 \\
\hline 19 & $133,134,135,136,137,138$ & 0.6062 & 0.1002 & 0.1050 & 0.1000 & 0.1004 \\
\hline 20 & $140,143,146,149,152$ & 5.4393 & 5.1359 & 5.3707 & 5.5172 & 5.4760 \\
\hline 21 & $\begin{array}{c}120,121,123,124,126,127,129,130,141 \\
142,144,145,147,148,150,151\end{array}$ & 1.8435 & 2.1181 & 2.0645 & 2.2032 & 2.1169 \\
\hline 22 & $153,154,155,156$ & 0.8955 & 0.9200 & 0.5443 & 0.8659 & 0.6939 \\
\hline 23 & $157,160,163,166,169$ & 8.1759 & 7.3084 & 7.6497 & 7.6477 & 7.6912 \\
\hline 24 & $171,172,173,174,175,176$ & 0.3209 & 0.1185 & 0.1000 & 0.1000 & 0.1332 \\
\hline 25 & $178,181,184,187,190$ & 10.98 & 7.6901 & 7.6754 & 8.1273 & 7.9972 \\
\hline 26 & $\begin{array}{c}158,159,161,162,164,165,167,168,179 \\
180,182,183,185,186,188,189\end{array}$ & 2.9489 & 3.0895 & 2.7178 & 2.9665 & 2.7859 \\
\hline 27 & $191,192,193,194$ & 10.5243 & 10.6462 & 10.8141 & 10.2386 & 10.4331 \\
\hline 28 & $195,197,198,200$ & 20.4271 & 20.7190 & 21.6349 & 20.6364 & 21.2289 \\
\hline 29 & 196,199 & 19.0983 & 11.7463 & 10.3520 & 11.6468 & 10.7392 \\
\hline Weight (kg) & & $2,298.61$ & $2,161.15$ & $2,158.08$ & $2,195.469$ & $2,156.62$ \\
\hline $\begin{array}{l}\text { Average optimized } \\
\text { weight }(\mathrm{kg})\end{array}$ & & $\mathrm{N} / \mathrm{A}$ & $2,447.52$ & $2,159.93$ & $\mathrm{~N} / \mathrm{A}$ & $2,159.46$ \\
\hline $\begin{array}{l}\text { Standard deviation on } \\
\text { average weight }(\mathrm{kg})\end{array}$ & & $\mathrm{N} / \mathrm{A}$ & 301.29 & 1.57 & $\mathrm{~N} / \mathrm{A}$ & 2.79 \\
\hline $\begin{array}{c}\text { Number of } \\
\text { structural analyses }\end{array}$ & & N/A & 10,500 & 14,700 & 9,000 & 16,420 \\
\hline
\end{tabular}


of member groups are also shown in this figure. The modulus of elasticity is $29 \mathrm{Msi}$ (200 GPa), and the yield stress is $36 \mathrm{ksi}(248.2 \mathrm{MPa})$. The effective length factors of the members are calculated as $k_{x} \geq 0$ for a sway-permitted frame, and the out-of-plane effective length factor is specified as $k_{y}=1.0$. Each column is considered as non-braced along its length, and the nonbraced length for each beam member is specified as onefifth of the span length. Limitations on displacement and strength are imposed according to the provisions of the AISC [31] as follows:

(a) Maximum lateral displacement:

$$
\frac{\Delta_{T}}{H}-R \leq 0,
$$

where $\Delta T$ is the maximum lateral displacement, $H$ is the height of the frame structure, and $R$ is the maximum drift index which is equal to $1 / 300$.

(b) The inter-story displacements:

$$
\frac{d_{i}}{h_{i}}-R_{I} \leq 0, \quad i=1,2, \ldots, n s,
$$

where $d_{i}$ is the inter-story drift, $h_{i}$ is the story height of the $i$ th floor, $n s$ is the total number of stories, and $R_{I}$ is the inter-story drift index $(1 / 300)$.

(c) Strength constraints:

$$
\left\{\begin{array}{l}
\frac{P_{u}}{2 \phi_{c} P_{n}}+\frac{M_{u}}{\phi_{b} M_{n}}-1 \leq 0, \quad \text { for } \frac{P_{u}}{\phi_{c} P_{n}}<0.2 \\
\frac{P_{u}}{\phi_{c} P_{n}}+\frac{8 M_{u}}{9 \phi_{b} M_{n}}-1 \leq 0, \quad \text { for } \frac{P_{u}}{\phi_{c} P_{n}} \geq 0.2
\end{array}\right.
$$

where $P_{u}$ is the required strength (tension or compression), $P_{n}$ is the nominal axial strength (tension or compression), $\phi_{c}$ is the resistance factor $\left(\phi_{c}=\right.$ 0.9 for tension, $\phi_{c}=0.85$ for compression), $M_{u}$ is the required flexural strengths, $M_{n}$ is the nominal flexural strengths, and $\phi_{b}$ denotes the flexural resistance reduction factor $\left(\phi_{b}=0.90\right)$.

The nominal tensile strength for yielding in the gross section is calculated by:

$$
P_{n}=A_{g} \cdot F_{y} .
$$

The nominal compressive strength of a member is computed as:

$$
P_{n}=A_{g} \cdot F_{c r},
$$

where:

$$
\begin{aligned}
& \begin{cases}F_{c r}=\left(0.658^{\lambda_{c}^{2}}\right) F_{y}, & \text { for } \lambda_{c} \leq 1.5 \\
F_{c r}=\left(\frac{0.877}{\lambda_{c}^{2}}\right) F_{y}, & \text { for } \lambda_{c}>1.5\end{cases} \\
& \lambda_{c}=\frac{k l}{r \pi} \sqrt{\frac{F_{y}}{E}},
\end{aligned}
$$

where $A_{g}$ is the cross-sectional area of a member,

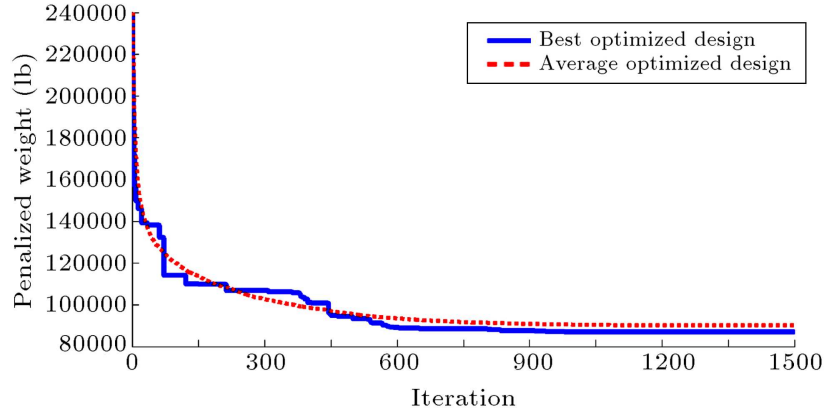

Figure 14. Convergence curves obtained for the 3-bay 15 -story frame structure.

and $k$ is the effective length factor calculated by [32]:

$$
k=\sqrt{\frac{1.6 G_{A} G_{B}+4.0\left(G_{A}+G_{B}\right)+7.5}{G_{A}+G_{B}+7.5}},
$$

where $G_{A}$ and $G_{B}$ are stiffness ratios of columns and girders at the two end joints, $A$ and $B$, of the column section, respectively.

Also, in this example, the sway of the top story is limited to 9.25 in $(23.5 \mathrm{~cm})$.

Table 9 presents the comparison of the results of the present algorithm with the outcomes of other algorithms. The proposed method yields the least weight for this example, which is $86,985 \mathrm{lb}$. The other design weights are $95,850 \mathrm{lb}$ by HPSACO (a hybrid algorithm of harmony search, particle swarm, and ant colony) [33], 97,689 lb by HBB-BC (a hybrid big bang-big crunch optimization) [34], 93,846 lb by ICA (Imperialist Competitive Algorithm) [35], 92,723 lb by CSS [36], 86,986 lb by ECBO [37], 93,315 lb by ESDE (Eagle Strategy with Differential Evolution) [38], and $91,248 \mathrm{lb}$ by DSOS (Discrete Symbiotic Organisms Search) [39]. The best design of VPS has been achieved in 19,600 analyses. It should be noted that the proposed method achieved about 92,000 lb (the best weight among the other methods except ECBO) after 10,800 structural analyses. Figure 14 provides the convergence rates of the best and average results found by the VPS. Element stress ratio and interstory drift evaluated at the best design optimized by VPS are shown in Figure 15. The maximum stress ratio is $99.88 \%$, and the maximum inter-story drift is 45.41 .

\subsection{A 3-bay 24-story frame problem}

The last structural optimization problem solved in this study is the weight minimization of the 3-bay 24story frame schematized in Figure 16. Frame members are collected in 20 groups (16 column groups and 4 beam groups). Each of the four beam element groups is chosen from all $267 \mathrm{~W}$-shapes, while the 16 
Table 9. Performance comparison for the 3-bay 15-story frame structure.

\begin{tabular}{|c|c|c|c|c|c|c|c|c|}
\hline \multirow[b]{2}{*}{$\begin{array}{l}\text { Element } \\
\text { group }\end{array}$} & \multicolumn{8}{|c|}{ Optimal W-shaped sections } \\
\hline & $\begin{array}{c}\text { HPSACO } \\
{[33]} \\
\end{array}$ & $\begin{array}{c}\text { HBB-BC } \\
{[34]} \\
\end{array}$ & $\begin{array}{c}\text { ICA } \\
{[35]} \\
\end{array}$ & $\begin{array}{l}\text { CSS } \\
{[36]} \\
\end{array}$ & $\begin{array}{c}\text { ECBO } \\
{[37]} \\
\end{array}$ & $\begin{array}{c}\text { ES-DE } \\
{[38]}\end{array}$ & $\begin{array}{c}\text { DSOS } \\
{[39]} \\
\end{array}$ & $\begin{array}{c}\text { Present } \\
\text { work }\end{array}$ \\
\hline 1 & $\mathrm{~W} 21 \times 111$ & $\mathrm{~W} 24 \times 117$ & $\mathrm{~W} 24 \times 117$ & $\mathrm{~W} 21 \times 147$ & W14×99 & $\mathrm{W} 18 \times 106$ & $\mathrm{~W} 16 \times 100$ & $\mathrm{~W} 14 \times 90$ \\
\hline 2 & $\mathrm{~W} 18 \times 158$ & $\mathrm{~W} 21 \times 132$ & $\mathrm{~W} 21 \times 147$ & $\mathrm{~W} 18 \times 143$ & $\mathrm{~W} 27 \times 161$ & $\mathrm{~W} 36 \times 150$ & $\mathrm{~W} 32 \times 152$ & $\mathrm{~W} 36 \times 170$ \\
\hline 3 & $\mathrm{~W} 10 \times 88$ & $\mathrm{~W} 12 \times 95$ & $\mathrm{~W} 27 \times 84$ & $\mathrm{~W} 12 \times 87$ & $\mathrm{~W} 27 \times 84$ & $\mathrm{~W} 12 \times 79$ & $\mathrm{~W} 12 \times 79$ & $\mathrm{~W} 14 \times 82$ \\
\hline 4 & $\mathrm{~W} 30 \times 116$ & $\mathrm{~W} 18 \times 119$ & $\mathrm{~W} 27 \times 114$ & $\mathrm{~W} 30 \times 108$ & $\mathrm{~W} 24 \times 104$ & $\mathrm{~W} 27 \times 114$ & $\mathrm{~W} 27 \times 114$ & $\mathrm{~W} 24 \times 104$ \\
\hline 5 & $\mathrm{~W} 21 \times 83$ & $\mathrm{~W} 21 \times 93$ & $\mathrm{~W} 14 \times 74$ & $\mathrm{~W} 18 \times 76$ & $\mathrm{~W} 14 \times 61$ & $\mathrm{~W} 30 \times 90$ & $\mathrm{~W} 21 \times 93$ & $\mathrm{~W} 21 \times 68$ \\
\hline 6 & $\mathrm{~W} 24 \times 103$ & $\mathrm{~W} 18 \times 97$ & $\mathrm{~W} 18 \times 86$ & $\mathrm{~W} 24 \times 103$ & $\mathrm{~W} 30 \times 90$ & $\mathrm{~W} 10 \times 88$ & $\mathrm{~W} 12 \times 79$ & $\mathrm{~W} 18 \times 86$ \\
\hline 7 & $\mathrm{~W} 21 \times 55$ & $\mathrm{~W} 18 \times 76$ & $\mathrm{~W} 12 \times 96$ & $\mathrm{~W} 21 \times 68$ & $\mathrm{~W} 14 \times 48$ & $\mathrm{~W} 18 \times 71$ & $\mathrm{~W} 21 \times 55$ & $\mathrm{~W} 21 \times 48$ \\
\hline 8 & $\mathrm{~W} 27 \times 114$ & $\mathrm{~W} 18 \times 65$ & $\mathrm{~W} 24 \times 68$ & $\mathrm{~W} 14 \times 61$ & $\mathrm{~W} 14 \times 61$ & $\mathrm{~W} 18 \times 65$ & $\mathrm{~W} 14 \times 61$ & $\mathrm{~W} 14 \times 61$ \\
\hline 9 & $\mathrm{~W} 10 \times 33$ & $\mathrm{~W} 18 \times 60$ & $\mathrm{~W} 10 \times 39$ & $\mathrm{~W} 18 \times 35$ & $\mathrm{~W} 14 \times 30$ & $\mathrm{~W} 8 \times 28$ & $\mathrm{~W} 14 \times 22$ & $\mathrm{~W} 12 \times 30$ \\
\hline 10 & $\mathrm{~W} 18 \times 46$ & $\mathrm{~W} 10 \times 39$ & $\mathrm{~W} 12 \times 40$ & $\mathrm{~W} 10 \times 33$ & $\mathrm{~W} 12 \times 40$ & $\mathrm{~W} 12 \times 40$ & $\mathrm{~W} 14 \times 43$ & $\mathrm{~W} 10 \times 39$ \\
\hline 11 & $\mathrm{~W} 21 \times 44$ & $\mathrm{~W} 21 \times 48$ & $\mathrm{~W} 21 \times 44$ & $\mathrm{~W} 21 \times 44$ & $\mathrm{~W} 21 \times 44$ & $\mathrm{~W} 21 \times 48$ & $\mathrm{~W} 21 \times 48$ & $\mathrm{~W} 21 \times 44$ \\
\hline Weight (lb) & 95,850 & 97,689 & 93,846 & 92,723 & 86,986 & 93,315 & 91,248 & 86,985 \\
\hline $\begin{array}{l}\text { Average optimized } \\
\text { weight }(\mathrm{lb})\end{array}$ & $\mathrm{N} / \mathrm{A}$ & $\mathrm{N} / \mathrm{A}$ & $\mathrm{N} / \mathrm{A}$ & $\mathrm{N} / \mathrm{A}$ & 88,410 & 98,531 & $\mathrm{~N} / \mathrm{A}$ & 90,066 \\
\hline $\begin{array}{c}\text { Standard deviation } \\
\text { on average weight (lb) }\end{array}$ & $\mathrm{N} / \mathrm{A}$ & $\mathrm{N} / \mathrm{A}$ & $\mathrm{N} / \mathrm{A}$ & $\mathrm{N} / \mathrm{A}$ & $\mathrm{N} / \mathrm{A}$ & 3,294 & $\mathrm{~N} / \mathrm{A}$ & 2,533 \\
\hline $\begin{array}{c}\text { Number of } \\
\text { structural analyses }\end{array}$ & 6,800 & 9,900 & 6,000 & 5,000 & 9,000 & 10,000 & $\mathrm{~N} / \mathrm{A}$ & 19,600 \\
\hline
\end{tabular}

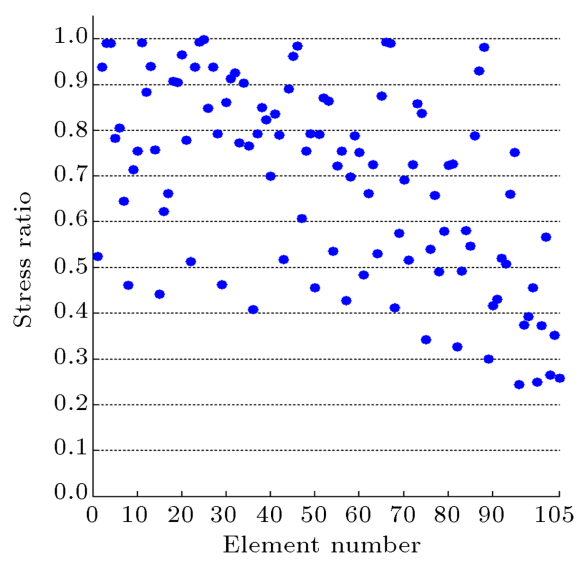

(a)

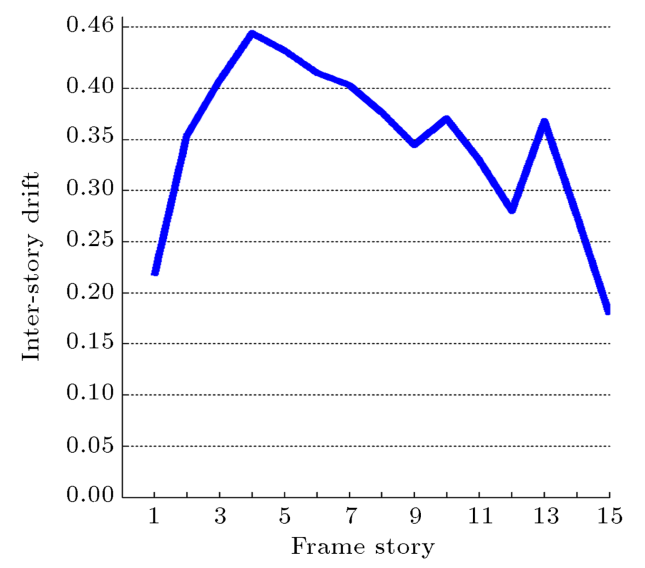

(b)

Figure 15. Constraint margins for the best design obtained by VPS for the 3-bay 15-story frame problem: (a) Element stress ratio and (b) inter-story drift.

column element groups are limited to W14 sections. The material has a modulus of elasticity equal to $E=29.732 \mathrm{Msi}(205 \mathrm{GPa})$ and a yield stress of $f_{y}=33.4 \mathrm{ksi}(230.3 \mathrm{MPa})$. The effective length factors of the members are calculated as $k x \geq 0$ for a sway-permitted frame, and the out-of-plane effective length factor is specified as $k_{y}=1.0$. All columns and beams are considered as non-braced along their lengths. Similar to the previous example, the frame is designed following the LRFD-AISC specification, and it uses an inter-story drift displacement constraint (AISC [31]).

This steel frame structure has been previously optimized by GA (Genetic Algorithm) [40], ACO (Ant Colony Optimization) [41], HS (Harmony Search) [42], CSS [36], ECBO [37], ES-DE [38], and DSOS [39]. Table 10 presents a comparison between the results of the optimal designs reported in the literature and the 
Table 10. Performance comparison for the 3-bay 24-story frame structure.

\begin{tabular}{|c|c|c|c|c|c|c|c|c|}
\hline \multirow[b]{2}{*}{$\begin{array}{l}\text { Element } \\
\text { group }\end{array}$} & \multicolumn{8}{|c|}{ Optimal W-shaped sections } \\
\hline & $\begin{array}{l}\text { GA } \\
{[40]}\end{array}$ & $\begin{array}{c}\mathrm{ACO} \\
{[41]}\end{array}$ & $\begin{array}{l}\text { HS } \\
{[42]}\end{array}$ & $\begin{array}{l}\text { CSS } \\
{[36]} \\
\end{array}$ & $\begin{array}{c}\text { ECBO } \\
{[37]} \\
\end{array}$ & $\begin{array}{c}\text { ES-DE } \\
{[38]}\end{array}$ & $\begin{array}{c}\text { DSOS } \\
{[39]}\end{array}$ & $\begin{array}{c}\text { Present } \\
\text { work }\end{array}$ \\
\hline 1 & $838 \times 292 \times 194 \mathrm{UB}$ & $\mathrm{W} 30 \times 90$ & $\mathrm{~W} 30 \times 90$ & $\mathrm{~W} 30 \times 90$ & W30 $\times 90$ & $\mathrm{~W} 30 \times 90$ & $\mathrm{~W} 30 \times 90$ & $\mathrm{~W} 30 \times 90$ \\
\hline 2 & $305 \times 102 \times 25 \mathrm{UB}$ & $\mathrm{W} 8 \times 18$ & $\mathrm{~W} 10 \times 22$ & $\mathrm{~W} 21 \times 50$ & $\mathrm{~W} 6 \times 15$ & $\mathrm{~W} 21 \times 55$ & $\mathrm{~W} 21 \times 62$ & $\mathrm{~W} 8 \times 18$ \\
\hline 3 & $457 \times 191 \times 82 \mathrm{UB}$ & $\mathrm{W} 24 \times 55$ & $\mathrm{~W} 18 \times 40$ & $\mathrm{~W} 21 \times 48$ & $\mathrm{~W} 24 \times 55$ & $\mathrm{~W} 21 \times 48$ & $\mathrm{~W} 21 \times 48$ & $\mathrm{~W} 21 \times 48$ \\
\hline 4 & $305 \times 102 \times 25 \mathrm{UB}$ & $\mathrm{W} 8 \times 21$ & $\mathrm{~W} 12 \times 16$ & $\mathrm{~W} 12 \times 19$ & $\mathrm{~W} 6 \times 8.5$ & $\mathrm{~W} 10 \times 45$ & $\mathrm{~W} 21 \times 55$ & $\mathrm{~W} 6 \times 8.5$ \\
\hline 5 & $305 \times 102 \times 25 \mathrm{UC}$ & $\mathrm{W} 14 \times 145$ & $\mathrm{~W} 14 \times 176$ & $\mathrm{~W} 14 \times 176$ & $\mathrm{~W} 14 \times 145$ & $\mathrm{~W} 14 \times 145$ & $\mathrm{~W} 14 \times 176$ & $\mathrm{~W} 14 \times 176$ \\
\hline 6 & $305 \times 368 \times 129 \mathrm{UC}$ & $\mathrm{W} 14 \times 132$ & $\mathrm{~W} 14 \times 176$ & $\mathrm{~W} 14 \times 145$ & $\mathrm{~W} 14 \times 132$ & W14×109 & $\mathrm{W} 14 \times 109$ & $\mathrm{~W} 14 \times 145$ \\
\hline 7 & $305 \times 305 \times 97 \mathrm{UC}$ & $\mathrm{W} 14 \times 132$ & $\mathrm{~W} 14 \times 132$ & $\mathrm{~W} 14 \times 109$ & W14×99 & $\mathrm{W} 14 \times 99$ & $\mathrm{~W} 14 \times 120$ & W14×99 \\
\hline 8 & $356 \times 368 \times 129 \mathrm{UC}$ & $\mathrm{W} 14 \times 132$ & $\mathrm{~W} 14 \times 109$ & $\mathrm{~W} 14 \times 90$ & $\mathrm{~W} 14 \times 90$ & $\mathrm{~W} 14 \times 145$ & $\mathrm{~W} 14 \times 82$ & $\mathrm{~W} 14 \times 82$ \\
\hline 9 & $305 \times 305 \times 97 \mathrm{UC}$ & $\mathrm{W} 14 \times 68$ & $\mathrm{~W} 14 \times 82$ & $\mathrm{~W} 14 \times 74$ & $\mathrm{~W} 14 \times 74$ & $\mathrm{~W} 14 \times 109$ & $\mathrm{~W} 14 \times 61$ & $\mathrm{~W} 14 \times 82$ \\
\hline 10 & $203 \times 203 \times 71 \mathrm{UC}$ & $\mathrm{W} 14 \times 53$ & $\mathrm{~W} 14 \times 74$ & $\mathrm{~W} 14 \times 61$ & $\mathrm{~W} 14 \times 38$ & $\mathrm{~W} 14 \times 48$ & $\mathrm{~W} 14 \times 99$ & $\mathrm{~W} 14 \times 38$ \\
\hline 11 & $305 \times 305 \times 118 \mathrm{UC}$ & $\mathrm{W} 14 \times 43$ & $\mathrm{~W} 14 \times 34$ & $\mathrm{~W} 14 \times 34$ & $\mathrm{~W} 14 \times 38$ & $\mathrm{~W} 14 \times 38$ & $\mathrm{~W} 14 \times 34$ & $\mathrm{~W} 14 \times 30$ \\
\hline 12 & $152 \times 152 \times 23 \mathrm{UC}$ & $\mathrm{W} 14 \times 43$ & $\mathrm{~W} 14 \times 22$ & $\mathrm{~W} 14 \times 34$ & $\mathrm{~W} 14 \times 22$ & $\mathrm{~W} 14 \times 30$ & $\mathrm{~W} 14 \times 38$ & $\mathrm{~W} 14 \times 30$ \\
\hline 13 & $305 \times 305 \times 137 \mathrm{UC}$ & $\mathrm{W} 14 \times 145$ & $\mathrm{~W} 14 \times 145$ & $\mathrm{~W} 14 \times 145$ & $\mathrm{~W} 14 \times 99$ & $\mathrm{~W} 14 \times 99$ & $\mathrm{~W} 14 \times 120$ & $\mathrm{~W} 14 \times 90$ \\
\hline 14 & $305 \times 305 \times 198 \mathrm{UC}$ & $\mathrm{W} 14 \times 145$ & $\mathrm{~W} 14 \times 132$ & $\mathrm{~W} 14 \times 132$ & $\mathrm{~W} 14 \times 99$ & $\mathrm{~W} 14 \times 132$ & $\mathrm{~W} 14 \times 109$ & W14×99 \\
\hline 15 & $356 \times 368 \times 202 \mathrm{UC}$ & $\mathrm{W} 14 \times 120$ & $\mathrm{~W} 14 \times 109$ & $\mathrm{~W} 14 \times 109$ & W14×99 & W14×109 & $\mathrm{W} 14 \times 90$ & $\mathrm{~W} 14 \times 99$ \\
\hline 16 & $356 \times 368 \times 129 \mathrm{UC}$ & $\mathrm{W} 14 \times 90$ & $\mathrm{~W} 14 \times 82$ & $\mathrm{~W} 14 \times 82$ & $\mathrm{~W} 14 \times 82$ & $\mathrm{~W} 14 \times 68$ & $\mathrm{~W} 14 \times 90$ & $\mathrm{~W} 14 \times 90$ \\
\hline 17 & $356 \times 368 \times 129 \mathrm{UC}$ & $\mathrm{W} 14 \times 90$ & $\mathrm{~W} 14 \times 61$ & $\mathrm{~W} 14 \times 68$ & $\mathrm{~W} 14 \times 68$ & $\mathrm{~W} 14 \times 68$ & $\mathrm{~W} 14 \times 82$ & $\mathrm{~W} 14 \times 61$ \\
\hline 18 & $356 \times 368 \times 153 \mathrm{UC}$ & $\mathrm{W} 14 \times 61$ & $\mathrm{~W} 14 \times 48$ & $\mathrm{~W} 14 \times 43$ & $\mathrm{~W} 14 \times 61$ & $\mathrm{~W} 14 \times 68$ & $\mathrm{~W} 14 \times 38$ & $\mathrm{~W} 14 \times 61$ \\
\hline 19 & $203 \times 203 \times 60 \mathrm{UC}$ & $\mathrm{W} 14 \times 30$ & $\mathrm{~W} 14 \times 30$ & $\mathrm{~W} 14 \times 34$ & $\mathrm{~W} 14 \times 30$ & $\mathrm{~W} 14 \times 61$ & $\mathrm{~W} 14 \times 38$ & $\mathrm{~W} 14 \times 34$ \\
\hline 20 & $254 \times 254 \times 89 \mathrm{UC}$ & $\mathrm{W} 14 \times 26$ & $\mathrm{~W} 14 \times 22$ & $\mathrm{~W} 14 \times 22$ & $\mathrm{~W} 14 \times 22$ & $\mathrm{~W} 14 \times 22$ & $\mathrm{~W} 14 \times 22$ & $\mathrm{~W} 14 \times 26$ \\
\hline Weight (lb) & 251,547 & 220,465 & 214,860 & 212,364 & 201,618 & 212,492 & 209,795 & 202,998 \\
\hline $\begin{array}{l}\text { Average optimized } \\
\text { weight (lb) }\end{array}$ & $\mathrm{N} / \mathrm{A}$ & 229,555 & 222,620 & 215,226 & 209,644 & $\mathrm{~N} / \mathrm{A}$ & $\mathrm{N} / \mathrm{A}$ & 212,289 \\
\hline $\begin{array}{l}\text { Standard deviation on } \\
\text { average weight (lb) }\end{array}$ & $\mathrm{N} / \mathrm{A}$ & 4,561 & $\mathrm{~N} / \mathrm{A}$ & 2,448 & $\mathrm{~N} / \mathrm{A}$ & $\mathrm{N} / \mathrm{A}$ & $\mathrm{N} / \mathrm{A}$ & 8,292 \\
\hline $\begin{array}{c}\text { Number of } \\
\text { structural analyses }\end{array}$ & 30,000 & 15,500 & 13,924 & 5,500 & 15,360 & 12,500 & 7,500 & 16,220 \\
\hline
\end{tabular}

present work. The lightest design (i.e., 201,618 lb) is found by ECBO algorithm, and after that, the best design belongs to VPS (i.e., 202,998 lb). The best design has been achieved at 16,220 analyses for VPS, and it has obtained 209,532 lb after 8,800 analyses, which is the best result compared to the weight achieved by the other method. Figure 17 provides the convergence rates of the best and average results found by the proposed method.

\section{Concluding remarks}

This paper presents a new population-based metaheuristic algorithm, called Vibrating Particles Sys- tem (VPS). This method is inspired by the damped free vibration of a single degree of freedom system. In the optimization process, particles gradually approach their equilibrium positions. To maintain the balance between local search and global search, these equilibrium positions are obtained from the current population and the historically best position. Two trusses and two frame benchmark structures are studied in order to show the performance of the VPS in terms of diversification, intensification, local optima avoidance, and convergence speed. The proposed algorithm finds superior optimal designs for three of the four problems investigated, illustrating the capability of the present method in solving constrained problems. 


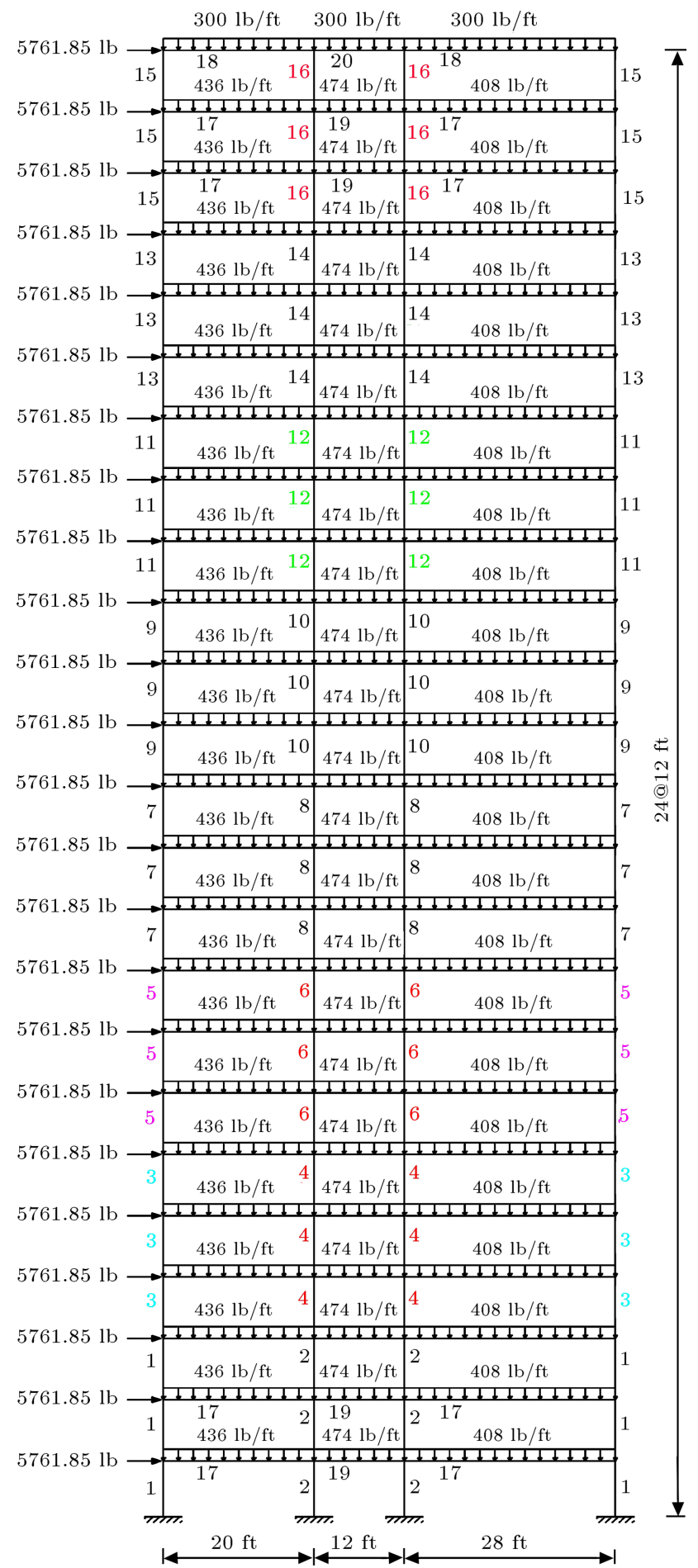

Figure 16. Schematic of the 3-bay 24-story frame.

Moreover, the average optimized results and standard deviation on averages results obtained by VPS are competitive with the other optimization methods. The convergence speed comparisons also reveal the fastconverging feature of the presented algorithm. For future research, it would be interesting to apply VPS to other optimization problems in different fields of science and engineering.

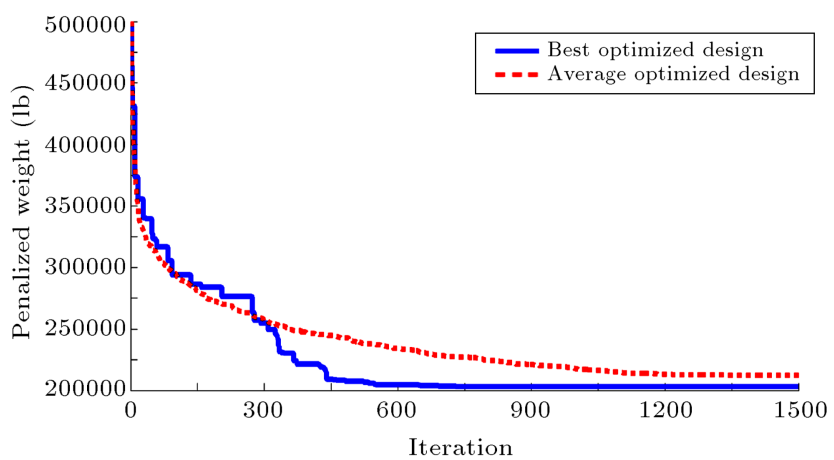

Figure 17. Convergence curves obtained for the 3-bay 24-story frame problem.

\section{Acknowledgments}

The first author is grateful to the Iran National Science Foundation for the support.

\section{References}

1. Holland, J.H. "Genetic algorithms", Sci Am., 267, pp. 66-72 (1992).

2. Kennedy, J. and Eberhart, R.C. "Particle swarm optimization", In Proceeding of IEEE of the International Conference on Neural Networks, pp. 1942-1948 (1995).

3. Dorigo, M., Maniezzo, V. and Colorni, A. "Ant system: optimization by a colony of cooperating agents", IEEE Trans Syst Man Cybernet Part B: Cybernet, 26(1), pp. 29-41 (1996).

4. Storn, R. and Price, K. "Differential evolution-a simple and efficient heuristic for global optimization over continuous spaces", J. Global Optim., 11, pp. 341-359 (1997).

5. Geem, Z.W., Kim, J.H. and Loganathan, G.V. "A new heuristic optimization algorithm: harmony search", Simulat., 76(2), pp. 60-68 (2001).

6. Erol, O.K. and Eksin, I. "A new optimization method: big bang-big crunch", Adv. Eng. Softw., 37, pp. 106111 (2006).

7. Karaboga, D. and Basturk, B. "A powerful and efficient algorithm for numerical function optimization: artificial bee colony (ABC) algorithm", J. Global Optim., 39, pp. 459-471 (2007).

8. Shah-Hosseini, H. "Principal components analysis by the galaxy-based search algorithm: a novel metaheuristic for continuous optimization", Int. J. Comput. Sci. Eng., 6, pp. 132-140 (2011).

9. Rao, R.V., Savsani, V.J. and Vakharia, D.P., "Teaching-learning-based optimization: a novel method for constrained mechanical design optimization problems", Comput Aided Des., 43(3), pp. 303-315 (2011).

10. Eskandar, H., Sadollah, A., Bahreininejad, A., and Hamdi, M. "Water cycle algorithm-A novel metaheuristic optimization method for solving constrained 
engineering optimization problems", Comput. Struct., 110, pp. 151-166 (2012).

11. Kaveh, A. and Mahdavi, V.R. "Colliding bodies optimization: A novel meta-heuristic method", Comput. Struct., 139, pp. 18-27 (2014).

12. Mirjalili, S., Mirjalili, S.M. and Lewis, A. "Grey wolf optimizer", Adv. Eng. Softw., 69, pp. 46-61 (2014).

13. Mirjalili S. "The ant lion optimizer", Adv. Eng. Softw., 83, pp. 80-98 (2015).

14. Kaveh, A. and Zolghadr, A. "A novel metaheuristic algorithm: tug of war optimization", Int. J. Optim. Civil. Eng., 6(4), pp. 469-492 (2016).

15. Mirjalili, S. and Lewis, A. "The whale optimization algorithm", Adv. Eng. Softw., 95, pp. 51-67 (2016).

16. Kaveh, A. and Bakhshpoori, T. "Water evaporation optimization: A novel physically inspired optimization algorithm", Comput. Struct., 167, pp. 69-85 (2016).

17. Lee, K.S. and Geem, Z.W. "A new structural optimization method based on the harmony search algorithm", Comput. Struct., 82, pp. 781-798 (2004).

18. Hasançebi, O., Çarbas, S., Dogan, E., Erdal, F. and Saka, M.P. "Performance evaluation of metaheuristic search techniques in the optimum design of real size pin jointed structures", Comput. Struct., 87(5-6), pp. 284-302 (2009).

19. Baghlani, A., Makiabadi, M.H. and Rahnema, H. "A new accelerated firefly algorithm for size optimization of truss structures", Sci. Iran., Transactions A, Civil Engineering, 20(6), pp. 1612-1625 (2013).

20. Baghlani, A. and Makiabadi, M.H. "An enhanced particle swarm optimization for design of pin connected structures", Sci. Iran., Transactions A, Civil Engineering, 20(5), pp. 1415-1432 (2013).

21. Kazemzadeh Azad, S. and Hasançebi, O. "Computationally efficient discrete sizing of steel frames via guided stochastic search heuristic", Comput Struct., 156, pp. 12-28 (2015).

22. Beer, F.P., Johnston, Jr E.R., Mazurek, D.F., Cornwell, P.J. and Self, B.P., Vector Mechanics for Engineers, McGraw-Hill Companies", New York, USA (2013).

23. Kaveh, A. and Talatahari, S. "Particle swarm optimizer, ant colony strategy and harmony search scheme hybridized for optimization of truss structures", Comput. Struct., 87(5), pp. 267-283 (2009).

24. American Institute of Steel Construction (AISC)., Manual of Steel Construction: Allowable Stress Design., American Institute of Steel Construction (1989).

25. Kaveh, A. and Talatahari, S. "Optimal design of skeletal structures via the charged system search algorithm", Struct. Multidiscip. Optim., 41, pp. 893-911 (2010).

26. Kaveh, A., Ilchi Ghazaan, M. and Bakhshpoori, T. "An improved ray optimization algorithm for design of truss structures", Period Polytech-Civ. Eng., 57(2), pp. 97-112 (2013).

27. Talatahari, S., Kheirollahi, M., Farahmandpour, C. and Gandomi, A.H. "A multi-stage particle swarm for optimum design of truss structures", Neural Comput. Appl., 23, pp. 1297-1309 (2013).

28. Kaveh, A. and Zolghadr, A. "Truss optimization with natural frequency constraints using a hybridized CSSBBBC algorithm with trap recognition capability", Comput. Struct., 102-103, pp. 14-27 (2012).

29. Kaveh, A. and Ilchi Ghazaan, M. "Enhanced colliding bodies algorithm for truss optimization with frequency constraints", J. Comput. Civil Eng., 29(6), (2014).

30. Kaveh, A. and Mahdavi, V.R. "A hybrid CBO-PSO algorithm for optimal design of truss structures with dynamic constraints", Appl. Soft. Comput., 34, pp. 260-273 (2015).

31. American Institute of Steel Construction (AISC), Manual of Steel Construction: Load and Resistance Factor Design., American Institute of Steel Construction (2001).

32. Dumonteil, P. "Simple equations for effective length factors", Eng. J. AISC., 29(3), pp. 111-115 (1992).

33. Kaveh, A. and Talatahari, S. "Hybrid algorithm of harmony search, particle swarm and ant colony for structural design optimization", Studies in Computational Intelligence, 239, pp. 159-198 (2009).

34. Kaveh, A. and Talatahari, S. "A discrete Big BangBig Crunch algorithm for optimal design of skeletal structures", Asian J. Civil Eng., 11(1), pp. 103-122 (2010).

35. Kaveh, A. and Talatahari, S. "Optimum design of skeletal structure using imperialist competitive algorithm", Comput. Struct., 88, pp. 1220-1229 (2010).

36. Kaveh, A. and Talatahari, S. "Charged system search for optimal design of frame structures", Appl. Soft. Comput., 12, pp. 382-393 (2012).

37. Kaveh, A. and Ilchi Ghazaan, M. "A comparative study of CBO and ECBO for optimal design of skeletal structures", Comput. Struct., 153, pp. 137-147 (2015).

38. Talatahari, S., Gandomi, A.H., Yang, X.S. and Deb, S. "Optimum design of frame structures using the eagle strategy with differential evolution", Eng. Struct., 91, pp. 16-25 (2015).

39. Talatahari, S. "Symbiotic organisms search for optimum design of frame and grillage system", Asian $J$. Civil Eng., 17(3), pp. 299-313 (2016).

40. Saka, M.P. and Kameshki, E.S. "Optimum design of frame multi-story sway steel frames to BS 5950 using a genetic algorithm", Advances in Engineering Computational Technology, pp. 135-141 (1998).

41. Camp, C.V., Bichon, B.J. and Stovall, S. "Design of steel frames using ant colony optimization", J. Struct. Eng., 131, pp. 369-379 (2005).

42. Degertekin, S.O. "Optimum design of steel frames 
using harmony search algorithm", Struct Multidiscip Optim., 36, pp. 393-401 (2008).

\section{Biographies}

Ali Kaveh was born in 1948 in Tabriz, Iran. After graduation from the Department of Civil Engineering in the University of Tabriz in 1969, he continued his studies on Structures at Imperial College of Science and Technology in London University and received his MSc, DIC and PhD degrees in 1970 and 1974, respectively. He then joined the Iran University of Science and Technology. Professor Kaveh is the author of 540 papers published in international journals and 145 papers presented at national and international conferences. He has authored 23 books in Persian and 8 books in English published by Wiley, Research Studies Press, American Mechanical Society, and Springer.

Majid Ilchi Ghazaan was born in Karaj, Iran, in 1988. He is currently pursuing the $\mathrm{Ph} . \mathrm{D}$. degree in Earthquake Engineering from the Department of Civil Engineering, Iran University of Science and Technology (IUST), Tehran, Iran. His main research interests include evolutionary algorithms and their applications in real-world problems. 